\title{
High-throughput sequencing of the 16S rRNA gene to analyze the gut microbiome in juvenile and adult tropical gar (Atractosteus tropicus)
}

\author{
Roberto Méndez-Pérez ${ }^{1}$, Rodrigo García-López ${ }^{3,4}$, J. Santiago Bautista-López ${ }^{1}$ \\ Jorge Vázquez-Castellanos ${ }^{3,4}$, Carlos Alvarez-González ${ }^{5}$, Emyr Peña-Marín ${ }^{5,6}$
}

Eduardo Baltierra-Trejo ${ }^{2,6}$, Randy Adams-Schroeder ${ }^{2}$, Verónica Domínguez-Rodríguez ${ }^{2}$ Carolina Melgar-Valdés ${ }^{7}$, Rafael Martínez-García ${ }^{5}$, Andrés Moya ${ }^{3,4}$ \& Rodolfo Gómez-Cruz ${ }^{1}$

${ }^{1}$ Biotech \& Environmental Genomics, Academic Body Environmental Sciences (CACIAM), Research Center for Conservation and Sustainable Use of Tropical Resources (CICART), Biological Sciences Academic

Division (DACBiol), Juárez Autonomous University of Tabasco State (UJAT)

Villahermosa, Tabasco, Mexico

${ }^{2}$ Biorremedation Laboratories, Academic Body Environmental Sciences (CACIAM), Research Center for

Conservation and Sustainable Use of Tropical Resources (CICART), Biological Sciences Academic Division

(DACBiol), Juárez Autonomous University of Tabasco State (UJAT)

Villahermosa, Tabasco, Mexico

${ }^{3}$ Department of Genomics and Health, Valencian Region Foundation for the Promotion of Health and

Biomedical Research (FISABIO), Valencia, Spain

${ }^{4}$ Integrative Systems Biology Institute (I2Sysbio), University of Valencia, Valencia, Spain

${ }^{5}$ Tropical Aquaculture Laboratory, CICART-DACBiol-UJAT, Villahermosa, Tabasco, Mexico

${ }^{6}$ Mexican National Council for Science and Technology (CONACyT)

${ }^{7}$ General Aquaculture Laboratory, Multidisciplinary Academic Division of the Rivers

(DAMRios)-UJAT, Tenosique, Tabasco, Mexico

Corresponding author: Rodolfo Gómez-Cruz (rodolfo.gomez@ujat.mx)

\begin{abstract}
Tropical gar (Atractosteus tropicus) is freshwater and estuarine fish, inhabiting the Earth since the Mesozoic era and undergoing limited physiological variation ever since. Besides its recognized cultural and scientific relevance, the species has seen remarkable growth in its economic impact due to pisciculture. In this study, we present the first report of the whole taxonomic composition of microbial communities in gut contents in juveniles and adults of A. tropicus, by sex and origin (wild and cultivated). For this study, 508 genera were identified, with the most and least abundant being Cetobacterium and Paludibacter, respectively. Fusobacteria, Proteobacteria, Firmicutes, and Bacteroidetes phyla are the core gut microbiome of A. tropicus juvenile and adult by sex and origin. Deinococcus-Thermus phylum sequence was only identified in wild-type males. In the phylogenetic trees reconstruction Lactococcus lactis strains CAU929 and CAU6600, Cp6 and CAU9951, Cetobacterium strain H69, Aeromonas hydrophila strain P5 and WR-5-3-2, Aeromonas sobria strain CP DC28 and Aeromonas hydrophila were identified, some of them with probiotic potential within the three dominant phyla in core gut microbiome in A. tropicus adults, especially in wild-type organisms. Myroides genus was recognized in microbiota gut of the cultivated juvenile A. tropicus. Nevertheless, Alpha diversity indicated that the highest gut microbiota abundance and richness is found in cultivated juvenile and wild-type adult $A$. tropicus female, rather than adult wild-type males and the least gut microbiota abundance and richness is found in a cultivated adult of $A$. tropicus for both sexes.
\end{abstract}

Keywords: Atractosteus tropicus; gut microbiome; metagenomics; 16S rRNA profiling

Corresponding editor: José Gallardo 


\section{INTRODUCTION}

Biological diversity in Latin America is one of the richest on the planet, including a great variety of its freshwater ichthyofauna (Flores-Nava \& Brown, 2010). Some of the most significant challenges for aquaculture, during this decade, have been done with integral studies on pisciculture-relevant endemic species, as well as the development of technologies that may allow for controlled production of these fishes in a profitable, innocuous, and environmentally-conscious approach (Márquez-Couturier \& Vázquez-Navarrete, 2015; Márquez-Couturier et al., 2015). In other fish species, some studies have explored the bacterial populations in varying habitats, such as the skin, gills, eggs and gut microbiome (GMBiom), and enhanced the way that they influenced the host's general health and physiology (MacFarlane et al., 1986; Cahill, 1990; Ringø et al., 1995; Givens, 2012; Austin et al., 2016). These studies have reported a significant variation of microbiota among different niches, and between species with the GMBiom as one of the most studied due to its high microorganism concentration. Thus, for the aquaculture industry, the effects caused by outbreaks of viral, bacterial, and fungal infections are of paramount importance, as they can cause devastating economic losses worldwide due to poor environmental conditions on farms, unbalanced feeding, the generation of toxins and genetic factors (Martínez-Cruz et al., 2012).

Tropical gar (Atractosteus tropicus), also known as "pejelagarto," is freshwater and an ample fossil record since the Cretaceous period of the Mesozoic Era (Wiley, 1976; Reséndez-Medina \& Salvadores, 1983). The species morphology has remained mostly unaltered, with current specimens having lengths between 1.0 and $1.2 \mathrm{~m}$ and weighing between 1,000 and $3,000 \mathrm{~g}$ in the wild. In their natural habitat, this species exists in coastal wetlands of the tropical rainy areas of southeastern Mexico, Belize, Guatemala, El Salvador, Honduras, Nicaragua and Costa Rica (Wiley, 1976; Bussing, 1987; Miller et al., 2005; Nelson et al., 2016). It has a carnivorous habit with some tendency to omnivorism, feeding on other fish, decomposing organic matter, crustaceans and plants depending on availability. This exceptionally secluded species has seen a drastic decrease in wild populations caused by anthropogenic activities that have led to the loss of habitats and severe ecological alterations (MéndezMarin et al., 2012). Currently, A. tropicus is cultivated in fish farms for human consumption in Mexico (Márquez-Couturier et al., 2015).

The gastrointestinal tract of A. tropicus is formed by the buccopharyngeal, esophagus, stomach, gut, pyloric blind, rectum and anus, which rapidly develops during the larval period (Frías-Quintana et al., 2015). The gut is a tubular structure beginning at the mouth and ending at the anus (Márquez-Couturier et al., 2006). The general character and even the length of the gut may change during ontogeny. For example, in fishes in which the larval stage is herbivorous, and the adult stage is carnivorous, the gut appears to shorten. In other fishes, the gut length remains relatively constant in proportion to body size throughout life (Smith, 1980). Early juveniles, 20 days after hatching, show a gut microbiota (GMBiot) like that of adults. Before colonization, microorganisms may access the GMBiot through food and water intake during the larval phase (Núñez de la Rosa, 2011). The high abundance of certain gastrointestinal bacteria groups in fish suggests that GMBiom poses as a unique niche for a specific but diverse group of bacteria (Cahill, 1990; Givens, 2012) when compared to the microbial composition of the surrounding water. It has been reported that GMBiot fish has between 107 and 1,011 bacteria per gram of feces (Nayak, 2010). GMBiot fish plays an important role and directly influences the host's nutrition and general homeostasis. Regular GMBiot fish may contain both beneficial and potentially pathogenic bacteria. The loss of the microbiota equilibrium (dysbiosis) has been reported to impact the host's physiological state, potentially compromising immunity, growth, general development as well as the overall quality of the aquaculture production due to an increase in fish morbidity and mortality (Al-Harbi \& Uddin, 2005; Núñez de la Rosa, 2011).

The advent of culture-independent metagenomic studies during the mid-2000s enabled the simultaneous analysis of complex genomic information contained in hundreds of microbial species in a single niche (Nielsen et al., 2014). These techniques circumvent most culturing requirements of microorganisms, avoiding collection and sampling biases, effectively representing the actual diversity of a microbial community. Under intensive production conditions for sustainable aquaculture, aquatic species are subjected to high-stress conditions, leading to an increased incidence of diseases that decrease productivity (Bondad-Reantaso et al., 2005). It has been proposed that microbiota dysbiosis may be avoided through the regulation of their microbiota (Verschuere et al., 2000).

Microbial studies in aquaculture focus on understanding the symbiotic or antagonistic interactions between microbes and their eukaryotic hosts such as fishes, crustaceans, and mollusks. In this sense, metagenomics can provide a deeper understanding of these relationships through information revealed by sequencing microbial DNA, extracted from specific 
niches within host organisms, and, in the case of $16 \mathrm{~S}$ profiling, taxa are representative of the medium (Suttle, 2007; Gianoulis et al., 2009). The latter consists of surveying the $16 \mathrm{~S}$ rRNA gene of all present microorganisms since this marker is found in all prokaryotes with enough mutations to discern each taxon. Formerly, some bacteria had been difficult to isolate because some of them are obligate intracellular microorganisms that could only be cultured in semiaqueous and or cell culture media (Avila-Villa et al., 2011). Current sequencing platforms and bioinformatics tools enable the research on the diversity of intracellular bacteria, but also ignore other culture requirements altogether, because the whole community DNA is sequenced as is, with majority and accessory species, to elucidate the relevant community configurations for the improvement of aquaculture techniques.

It was decided to evaluate the differences between sex since females are larger than males and have access to other types of prey. Also, nutritional and metabolic requirements are different between sex, so we assume that there should be differences in microbial communities due to the great intra- and inter-specific variations, which has been reported by Piazzon et al. (2019), where differences in the microbiome are associated with habitat, diet, trophic level, season, captivity, age, genetics, sex, among others. Consequently, the objective of this research was to explore the microbial composition in the gut of A. tropicus juvenile and adult, by analyzing the 16S rRNA gene profiles from adult male and female organisms, cultivated and wild, for biotechnological-relevant applications in the future.

\section{MATERIALS AND METHODS}

\section{Specimen collection}

Seventeen live Atractosteus tropicus organisms were collected for the study. Nine of them (seven adults + two juveniles) were cultivated in the Tropical Aquaculture Laboratory, Research Center for Conservation and Sustainable Use of Tropical Resources (CICART) at the Biological Sciences Academic Division (DACBiol), Juárez Autonomous University of Tabasco State (UJAT), Mexico. Eight were wild-type specimens, with an average weight and length of $5 \mathrm{~kg}$ and $1 \mathrm{~m}$, respectively. Specimens were provided by fishermen from the municipalities of Nacajuca $\left(18^{\circ} 14^{\prime} 50^{\prime \prime} \mathrm{N}\right.$, $92^{\circ} 49^{\prime} 58^{\prime \prime} \mathrm{W}$; n: female, m: male) and Centla $\left(18^{\circ} 20^{\prime} \mathrm{N}\right.$, $92^{\circ} 30^{\prime} \mathrm{W}$; n: female, m: male), Tabasco, Mexico (Fig. $1)$.

\section{Samples collection and preparation}

All organisms were sacrificed by stunning percussion method, according to the NOM-062-ZOO-1999 proto- col, on June 18, 2001, approved by The Ministry of Agriculture, Livestock, Rural Development, Fishing and Food. After the euthanasia method, all specimens were cut lengthwise under sterile environments to remove the intestine and extract its contents with scissors disinfected in absolute ethyl alcohol, for storage at $-20^{\circ} \mathrm{C}$ in a $2 \mathrm{~mL}$ Eppendorf tubes. GMBiot and feces were separated under sterile conditions, considering the origin (wild or domesticated) and sex.

\section{DNA extraction, sequencing, and sequence for meta- genomic analysis}

Two hundred milligrams of fresh feces were used, and $2 \mathrm{~mL}$ was enough to ensure the target DNA with the capacity of the Eppendorf tubes selected. A whole genomic DNA (gDNA) extraction was carried out for each sample with a QIAamp DNA Stool Mini Kit (Qiagen, Valencia, CA, USA), following the manufacturer's instructions. DNA integrity and concentration were evaluated by electrophoresis, submerged with $1.2 \%$ agarose gel, and by spectrophotometry with a GenovaNano spectrophotometer (Jenway, Stone, Staffs, UK), respectively. Universal primers 515F (5'GTGCCAGCMGCCGCGG TAA-3') (Caporaso et al., 2011) and 909R (5'-CCCCGYCAATTCMTTTRAGT3') (Tamaki et al., 2011) were selected for the amplification of a region including the V4 and V5 hypervariable region in the $16 \mathrm{~S}$ rRNA gene. PCR amplifications were carried out using Phusion HighFidelity DNA Polymerase (Finnzymes OY, Espoo, Finland) (Klindworth et al., 2013), and conditions were performed according to D'Auria et al. (2018). Library preparation and high throughput sequencing were performed through Research \& Testing Labs (Lubbock, Texas, USA) services, with an Illumina MiSeq platform, using 16S rDNA profiling by amplifying the V4-V5 hypervariable regions of the bacterial gene, reagents sequencing for $2 \times 300 \mathrm{bp}$ paired-end reads.

\section{Bioinformatics analysis}

The sequences were subjected to the standard quality protocols, which included the sequencing adapters' removal with the Cutadapt tool v.2.1 (Martin, 2011). The sequences were analyzed by a pipeline of the DADA2 package (Callahan et al., 2016), compatible with $\mathrm{R}$ (R Core Team, 2019). Through which the standard quality filters maxEE $=\mathrm{c}(2,5)$ and truncQ $=\mathrm{c}$ $(2,5)$ was applied, the Paired-end were joined, adjusting to a final length of $370 \mathrm{bp}$. The amplicon sequence variant table (ASV) was constructed, and chimeric sequences were eliminated by consensus identification. The ASV was used for the taxonomic assignment, which was performed with the classifier tool of the RDP's Pipeline (Ribosomal Database Project) (Wang et $a l ., 2007)$ with a confidence cutoff of $40 \%$. 


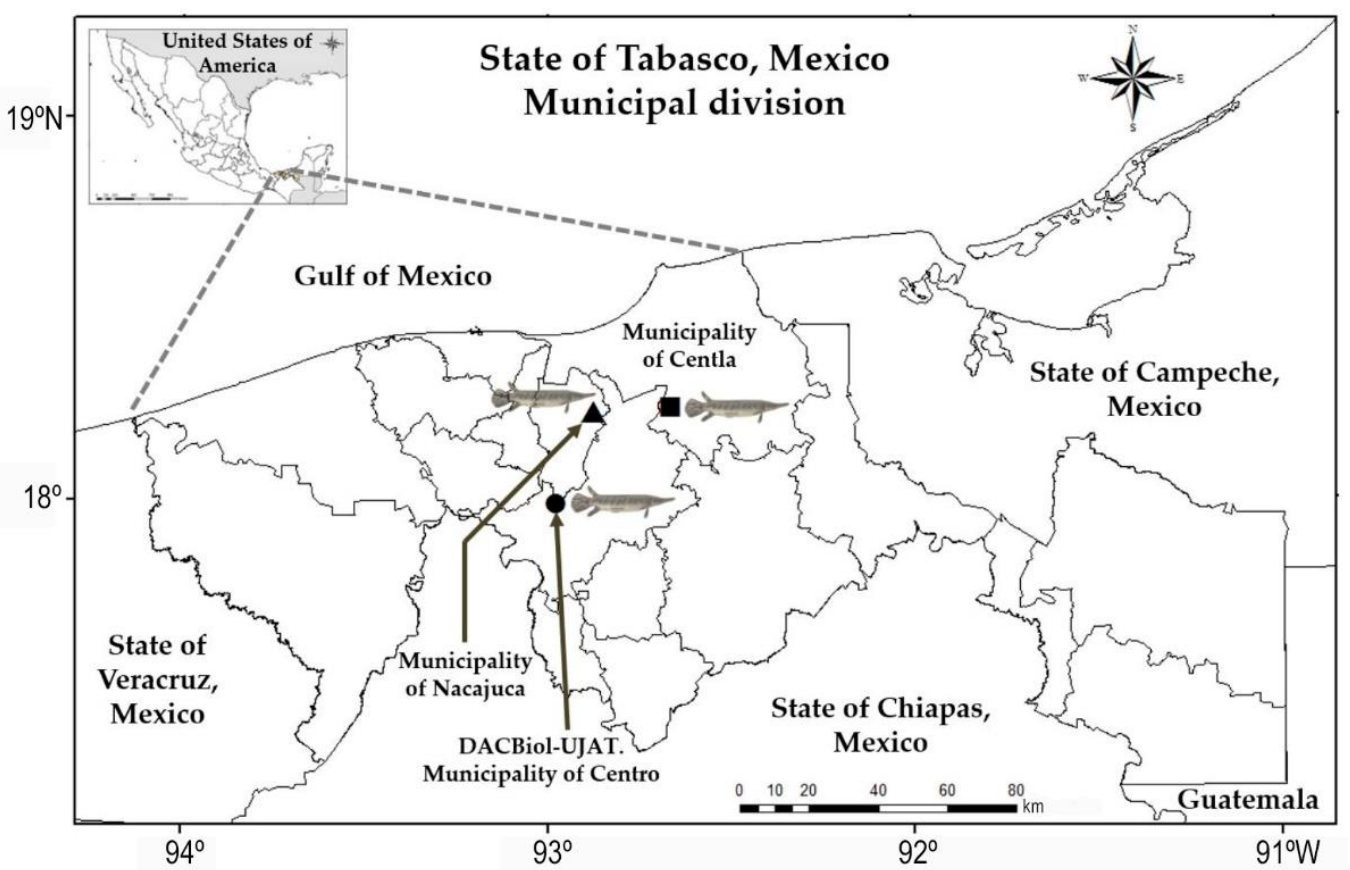

Figure 1. Tropical gars (Atractosteus tropicus) collection sites, wild-type adults (triangles shape identified), and cultivated juveniles/adults (circle shape identified).

\section{Alpha diversity}

The ASV table was normalized by rarefaction so that all the samples had the same number of sequences. The alpha diversity estimators of ACE, Pielou's evenness and Inverse Simpson, were calculated. Moreover, the statistical comparison of the diversity estimators among the sample groups analyzed was carried out using the nonparametric statistical tests of Kruskal-Wallis and Wilcoxon signed-rank. The value of $p$ was adjusted to 0.05 , and the FDR correction was applied to each analysis. The statistical analyses were performed in $\mathrm{R}$ (R Core Team, 2019).

\section{Beta diversity}

The ASV table was normalized using the CLR transformation (centered log-ratio) (Aitchison, 1982). This table was used for the construction of an Unweighted UniFrac distance matrix (Lozupone et al., 2011), to compare and analyze the A. tropicus microbial community composition and distance matrix, respectively, under cultivated and wild-type conditions, PCoA, and a beta significance test was used by adonis nonparametric statistical method. Multiple comparison analysis paired by PERMANOVA and differential analysis of abundance was compared to abundance patterns of the taxa between the samples groups by LEfSe tool (linear discriminant analysis effect size) to identify biomarkers in clustering results (Segata et al., 2011).

\section{Phylogenetic analysis}

A sequence base was constructed according to certain genera with probiotic potential in fish that we find in a literature search (Table 1); 16S rRNA gene sequences were obtained from the NCBI GenBank database. The 6,266 sequences obtained were clustered to eliminate identical sequences and generate a table of OTUs with 97\% similarity, using the usearch61 algorithm of QIIME (1.9). The database was indexed (Query Sequence) to be used in a local blast with the BLAST + tool (NCBI). The local blast was performed using the sequences of the samples (subject sequences) clustered at $97 \%$, as mentioned in the section on the processing of the sequences. The identity percentage was adjusted to $99 \%$ (-perc identity) and a coverage of $70 \%$ (-qcov_hsp_perc 70). For phylogenetic analysis, the blast resulting in Query and Subject sequences were subjec-ted to multiple alignments with the ClustalW algorithm, in MEGAX (Molecular Evolutionary Genetics Analysis), and the phylogenetic relationships were inferred by the Neighbor-joining method in MEGAx, with the predefined settings.

\section{RESULTS}

A total of 364,735 sequencing reads were generated, organized by sex and origin, according to Table 2 . We can see in Table 2 that readings obtained of wild-type 


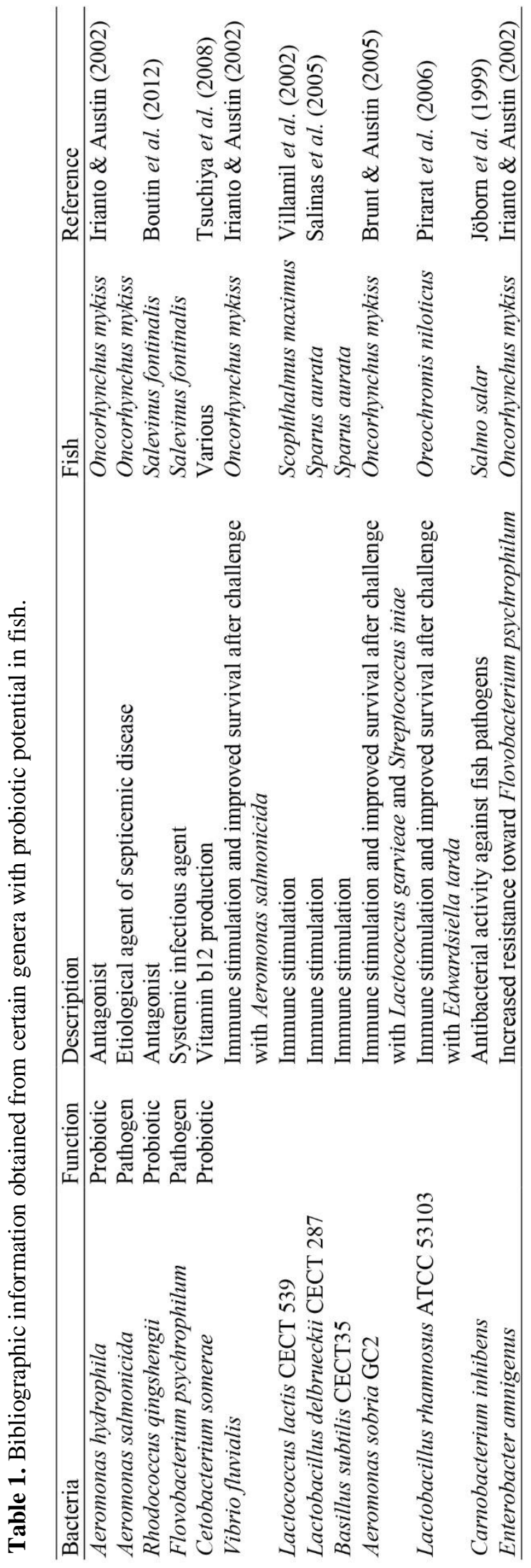

Table 2. Total reads by sex and origin.

\begin{tabular}{lrc}
\hline \multirow{2}{*}{ Organisms } & \multicolumn{2}{c}{ Reads } \\
\cline { 2 - 3 } & Wild-type & Cultivated \\
\hline Female & 99,513 & 59,539 \\
Male & 137,792 & 67,891 \\
Subtotal & 237,305 & 127,430 \\
\hline Total & \multicolumn{2}{c}{364,735} \\
\hline
\end{tabular}

male organisms are far higher than of wild-type and cultivated females, and cultivated males. Sequences were clustered into 16,503 different OTUs (97\% identity), which were classified into 11 phyla, 22 class, 37 order, 86 families, and 179 genera. Table 2 shows that about twice as many reads correspond to wild males.

\section{Microbiota composition}

The microbiota in the gut of Atractosteus tropicus adult is composed of the Fusobacteria (42.26\%), Proteobacteria (31.40\%), Firmicutes (12.96\%), and Bacteroidetes (11.79\%) phyla (Fig. 2a, Table 3). In wild-type females, the most abundant phyla were Proteobacteria (11.15\%), Firmicutes (3.87\%), Fusobacteria (2.49\%), and Bacteroidetes $(1.23 \%)$, and in cultivated females were the Fusobacteria $(8.70 \%)$, Proteobacteria $(6.48 \%)$, and Bacteroidetes (3.32\%). In wild-type and cultivated males, the most abundant phyla were Fusobacteria (15.36 and $15.65 \%$, respectively), and Proteobacteria (5.06 and $3.42 \%$, respectively) (Fig. 2a, Table 3 ). However, the cultivated juvenile $A$. tropicus gut microbiota is formed by the Firmicutes (5.33\%), Proteobacteria (5.28\%), and Bacteroidetes (2.93\%), only (Fig. 2a, Table 3 ). At the genus level, the most abundant were Cetobacterium (42.24\%), Serratia (13.02\%), Edwardsiella (9.46\%), Paludibacter (6.49\%) and Clostridium sensu stricto $(5.76 \%)$ in adult specimens by sex and origin, and in cultivated juveniles, Staphylococcus (2.62\%), Plesiocystis (2.56\%) and Myroides $(2.36 \%)$; whereas Edwardsiella (6.68\%) was more abundant in wild-type males' fish (Fig. 2b, Table 3). For the Cetobacterium $(42.24 \%)$ and Clostridium sensu stricto (15.09\%) genera, they are more abundant than Bacteroidetes and Actinobacteria in the cultivated and wild-type specimens, respectively (Fig. 2b). Likewise, the taxonomic composition of the more abundant phylogenetic groups by sex and origin in the microbiota of the A. tropicus gut at phylum, class, order, and family taxonomic levels (Figs. 3a-b and 4a-b), shows that the most abundant were Fusobacteria, Gammaproteobacteria, Enterobacterales, and Enterobacteriaceae, respectively (Figs. 3a-b and 4a-b). Although the primers are designed only for 16S rRNA gene amplification of bacteria, OTUs belonging to the Archaea 


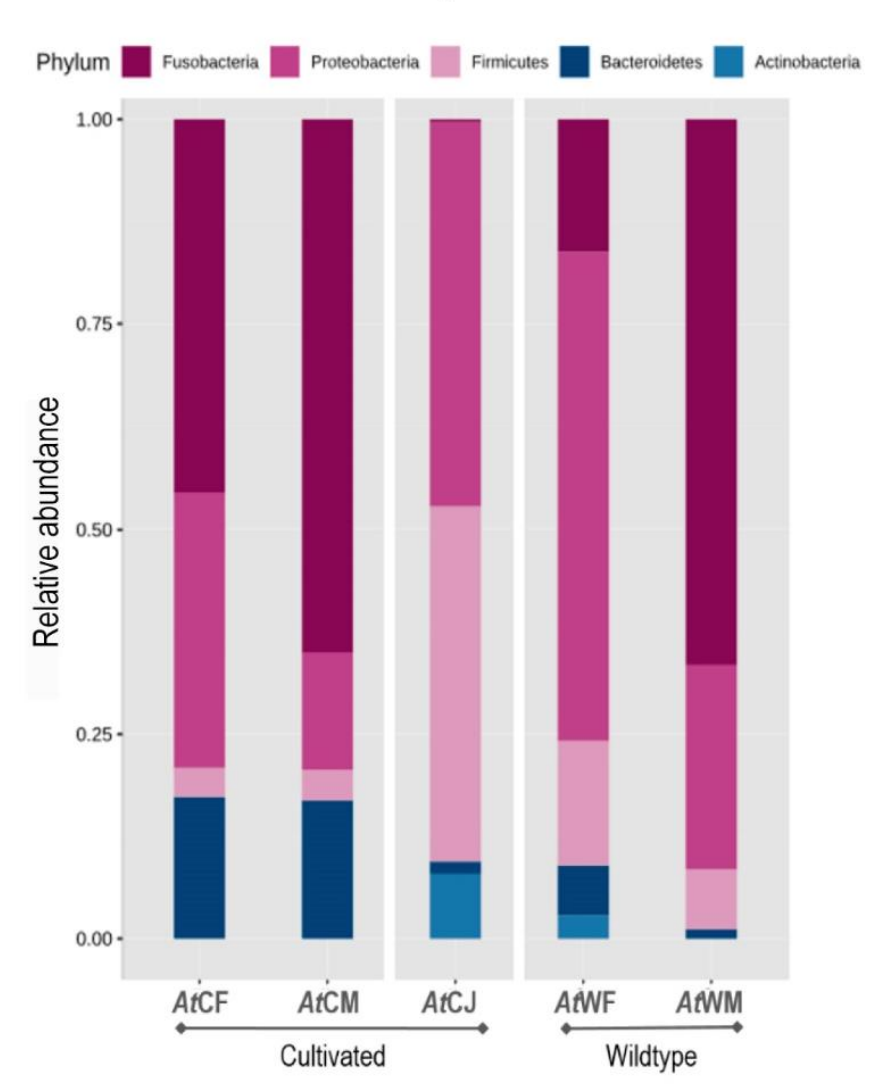

b

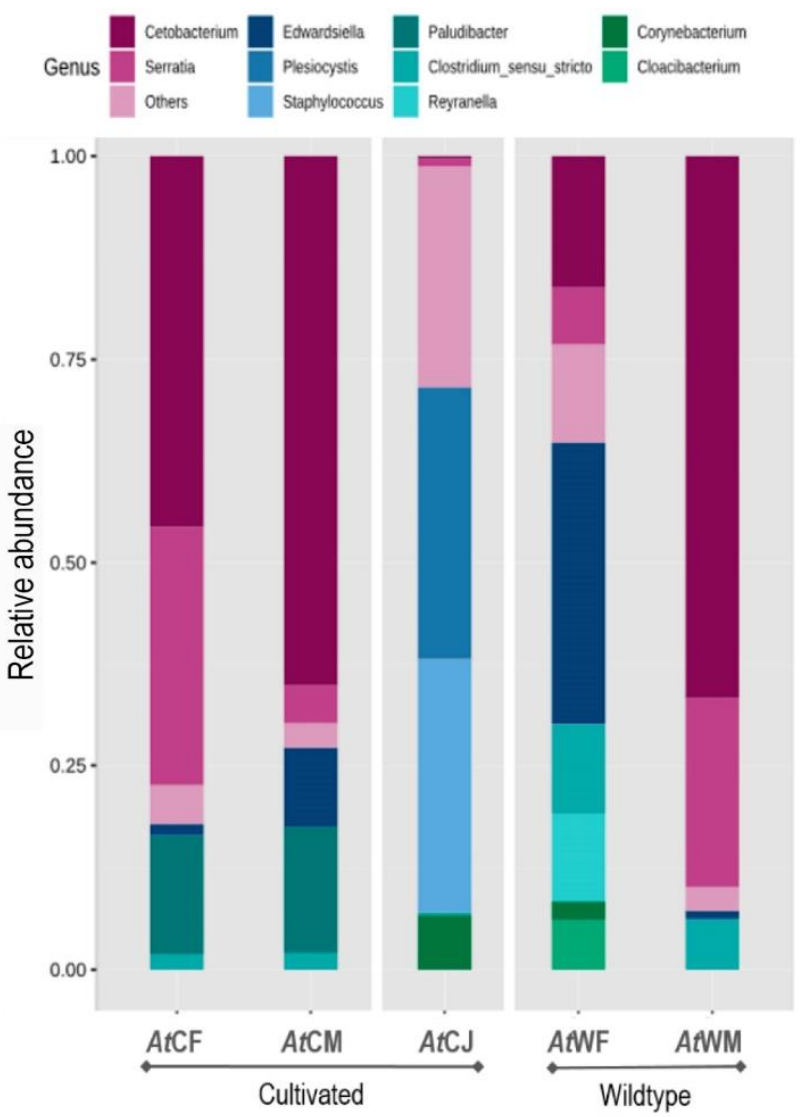

Figure 2. Core microbiome in Atractosteus tropicus gut, cultivated juvenile/adult and wild-type adult only, at taxonomic class-level of a) phylum and b) genus. Only taxa were plotted with abundance $\geq 1 \%$. AtFCF: cultivated adult females; AtCM: cultivated adult males; AtCJ: cultivated juveniles were collected in farm; AtWF: wild-type adult females; AtWM: wildtype adult male.

domain were also identified, represented by the genera Salinirubrum, Salinigranum, and Methano-culleus, which together represent about $0.01 \%$ of the total abundance.

\section{Alpha diversity}

In this research, diversity, dominance, and richness indicators were measured by the ACE index, using the same OTUs number (Table 4). The ACE index indicates the microbial types in A. tropicus are not distributed as uniformly and thus may be more diverse in cultivated juveniles (320.82 \pm 16.14$)$ and wild-type females $(103.57 \pm 3.97)$ and cultivated $(72.38 \pm 6.12)$ than in the cultivated $(48.62 \pm 4.63)$ and wild-type $(47.92 \pm 3.18)$ male individuals (Table 4). Significant differences were detected in the microbiotic diversity component, between juveniles and adults by sex and origin, only a few samples were not statistically significant. The cultivated juveniles, and wild-type and cultivated females turned out to be the most diverse, but by origin, only the cultivated juveniles and wild-type females were the most diverse. In a total of 50 taxa, significant differences can be observed between cultivated and wild conditions.

\section{Beta diversity}

Bacterial community's beta diversity associated with the gut in juvenile and adult A. tropicus on origin conditions were measured through the ordination analysis from Principal Coordinates Analysis (PCoA), using Unweighted Unifrac Distances (UniFrac). The analysis produced an ordination of the dissimilarities, where similar individuals are close to one another, and dissimilar ones are distant (Fig. 5). All ordination analyses showed a clear separation between wild-type and cultivated samples. The statistically significant differences by the origin and even more between the cultivated juvenile fish and the wild type ones (Fig. 5) were found by the ANOSIM statistic $(\mathrm{R}=0.60933, P<$ $0.002)$. 
Table 3. Composition and taxonomic structure of the adult and juvenile tropical gars (Atractosteus tropicus) gut samples at the phylum and genus levels, classified by their global abundance, by origin and sex/origin.

\begin{tabular}{|c|c|c|c|c|c|c|c|c|c|c|}
\hline \multirow{2}{*}{\multicolumn{2}{|c|}{ GENERAL }} & Phylum & Fusobacteria $42.26 \%$ & Proteobacteria $31.40 \%$ & Firmicutes $12.96 \%$ & Bacteroidetes $11.79 \%$ & & & & \\
\hline & & Genus & Cetobacterium $42.24 \%$ & Serratia $13.02 \%$ & Edwardsiella $9.46 \%$ & Paludibacter $6.49 \%$ & $\begin{array}{l}\text { Clostridium sensu } \\
\text { stricto } 5.76 \%\end{array}$ & & & \\
\hline \multirow{6}{*}{$\begin{array}{l}\frac{Z}{u} \\
\frac{u}{J}\end{array}$} & \multirow[b]{2}{*}{ c } & Phylum & Fusobacteria $24.35 \%$ & Proteobacteria $9.90 \%$ & & Bacteroidetes $7.39 \%$ & & & & \\
\hline & & Genus & Cetobacterium $73.06 \%$ & Serratia $21.48 \%$ & Edwardsiella $7.74 \%$ & Paludibacter $19.47 \%$ & $\begin{array}{l}\text { Clostridium sensu } \\
\text { stricto } 2.58 \%\end{array}$ & & & \\
\hline & \multirow[b]{2}{*}{ CJ } & Phylum & & Proteobacteria 5.28\% & Firmicutes $5.33 \%$ & Bacteroidetes $2.93 \%$ & & & & \\
\hline & & Genus & & & & & & $\begin{array}{c}\text { Staphylococcus } \\
2.62 \%\end{array}$ & $\begin{array}{c}\text { Plesiocystis } \\
2.56 \%\end{array}$ & $\begin{array}{c}\text { Myroides } \\
2.36 \%\end{array}$ \\
\hline & \multirow[b]{2}{*}{ W } & Phylum & Fusobacteria $17.86 \%$ & Proteobacteria $16.21 \%$ & Firmicutes $5.98 \%$ & & & & & \\
\hline & & Genus & Cetobacterium $17.86 \%$ & Serratia $5.78 \%$ & Edwardsiella $6.88 \%$ & & $\begin{array}{c}\text { Clostridium sensu } \\
\text { stricto } 4.84 \%\end{array}$ & & & \\
\hline \multirow{10}{*}{$n$} & \multirow{2}{*}{ AtCF } & Phylum & Fusobacteria $8.70 \%$ & Proteobacteria $6.48 \%$ & & Bacteroidetes $3.32 \%$ & & & & \\
\hline & & Genus & Cetobacterium $8.70 \%$ & Serratia $6.05 \%$ & & Paludibacter $2.74 \%$ & & & & \\
\hline & \multirow{2}{*}{ AtCM } & Phylum & Fusobacteria $15.65 \%$ & Proteobacteria $3.42 \%$ & & Bacteroidetes $4.06 \%$ & & & & \\
\hline & & Genus & Cetobacterium $15.65 \%$ & & Edwardsiella $2.31 \%$ & Paludibacter $3.74 \%$ & & & & \\
\hline & \multirow[b]{2}{*}{ AtCJ } & Phylum & & Proteobacteria 5.28\% & Firmicutes $5.33 \%$ & Bacteroidetes $2.93 \%$ & & & & \\
\hline & & Genus & & & & & & $\begin{array}{c}\text { Staphylococcus } \\
2.62 \%\end{array}$ & $\begin{array}{c}\text { Plesiocystis } \\
2.56 \%\end{array}$ & $\begin{array}{c}\text { Myroides } \\
2.36 \%\end{array}$ \\
\hline & \multirow[b]{2}{*}{ AtWF } & Phylum & Fusobacteria $2.49 \%$ & Proteobacteria $11.15 \%$ & Firmicutes $3.87 \%$ & Bacteroidetes $1.23 \%$ & & & & \\
\hline & & Genus & Cetobacterium $2.49 \%$ & & Edwardsiella $6.68 \%$ & & $\begin{array}{c}\text { Clostridium sensu } \\
\text { stricto } 2.96 \%\end{array}$ & & & \\
\hline & \multirow[b]{2}{*}{ AtWM } & Phylum & Fusobacteria $15.36 \%$ & Proteobacteria $5.06 \%$ & Firmicutes $2.10 \%$ & & & & & \\
\hline & & Genus & Cetobacterium $15.36 \%$ & Serratia $4.66 \%$ & & & $\begin{array}{l}\text { Clostridium sensu } \\
\text { stricto } 1.87 \%\end{array}$ & & & \\
\hline & $\begin{array}{l}\text { Ultivate } \\
\text { Cultivat } \\
\text { Nildtyp }\end{array}$ & $\begin{array}{l}\text { d } \\
\text { ed juvenil } \\
\text { e }\end{array}$ & & $\begin{array}{l}\text { AtCF }= \\
\text { AtCM }= \\
\text { AtCJ }=\mathrm{J}\end{array}$ & $\begin{array}{l}\text { dult } A \text {. tropicus cult } \\
\text { dult } A \text {. tropicus cul } \\
\text { veniles } A \text {. tropicus c }\end{array}$ & $\begin{array}{l}\text { ted females } \\
\text { ated males } \\
\text { tivated }\end{array}$ & & \multicolumn{3}{|c|}{$\begin{array}{l}\text { AtWF }=\text { Adult } A \text {. } \text { tropicus } \text { wildtype females } \\
\text { AtWM }=\text { Adult } A \text {. tropicus } \text { wildtype males }\end{array}$} \\
\hline
\end{tabular}

Beta diversity significance. The multiple pairwise comparison tests (MPC) were used for evaluating relationships between all family (group) permutations. The obtained MPC results of adonis tests showed all pairwise differences were statistically significant at an $\alpha=0.05$ (i.e., between cultivated adults and cultivated juveniles, between cultivated adults and WT adults, and between cultivated juvenile and WT adults; Table 5).

\section{Significant microbial components associated with origin and sex}

Eight genera were identified in wild organisms, and these are Methanoculleus, Flavobacterium, Psychrobacter, Acinetobacter, Pseudomonas, Paracoccus, Massilia, and Shewanella. Likewise, 13 genera were identified in cultivated organisms, which are Paludibacter, Intestinibacter, Cellulosilyticum, Odoribacter, Turicibacter, Defluviitalea, Vallitalea, Acetivibrio, Terrisporobacter, Bacteroides, Acidaminobacter, Sporacetigenium, and Macellibacteroides.

\section{Differential analysis of abundance}

Specific taxa distributed differentially between wild and cultivated fish were identified through the LefSe tool; this allows obtaining statistical differences for each taxon. Figures 6-8, shows a bar graph of linear discriminant analysis (LDA) by LefSe Biomarkers identification between cultivated juveniles and adults specimens were identified, which correspond to 98 taxa with differential abundance. Wild-type adults and cultivated juveniles showed 61 taxa with differential abundance, and wild-type and cultivated adults had 10 taxa with differential abundance.

\section{Phylogenetic reconstruction analysis}

The sequences-base of the rRNA 16S gene constructed of some organisms found in the literature with probiotic potential in fish, according to Table 1 , allowed us to find and identify possible organisms with probiotic potential in the microbiome gut of adult A. tropicus, adjusted to $99 \%$ identity and $70 \%$ coverage. In Figure 9 , we obtained a phylogenetic tree based on the identified sequences of the most abundant phyla per sample, such as Fusobacteria, Proteobacteria, and Firmicutes. Besides, we used Methanosarcina thermophila and Archaeoglobus profundus sequences data of thermophilic methanogens and sulfate-reducing archaea, respectively, as outgroups for the root identification, considering that they may be related only distantly with the identified sequences in our work.

In the phylogenetic tree reconstruction (Fig. 9), we determined that the evolutionary conclusion of these relationships is that the two species of Achaea or outgroups selected are ancestors of the nine species or ingroups identified with blue squares. Likewise, they belong to the three most dominant phyla groups that 


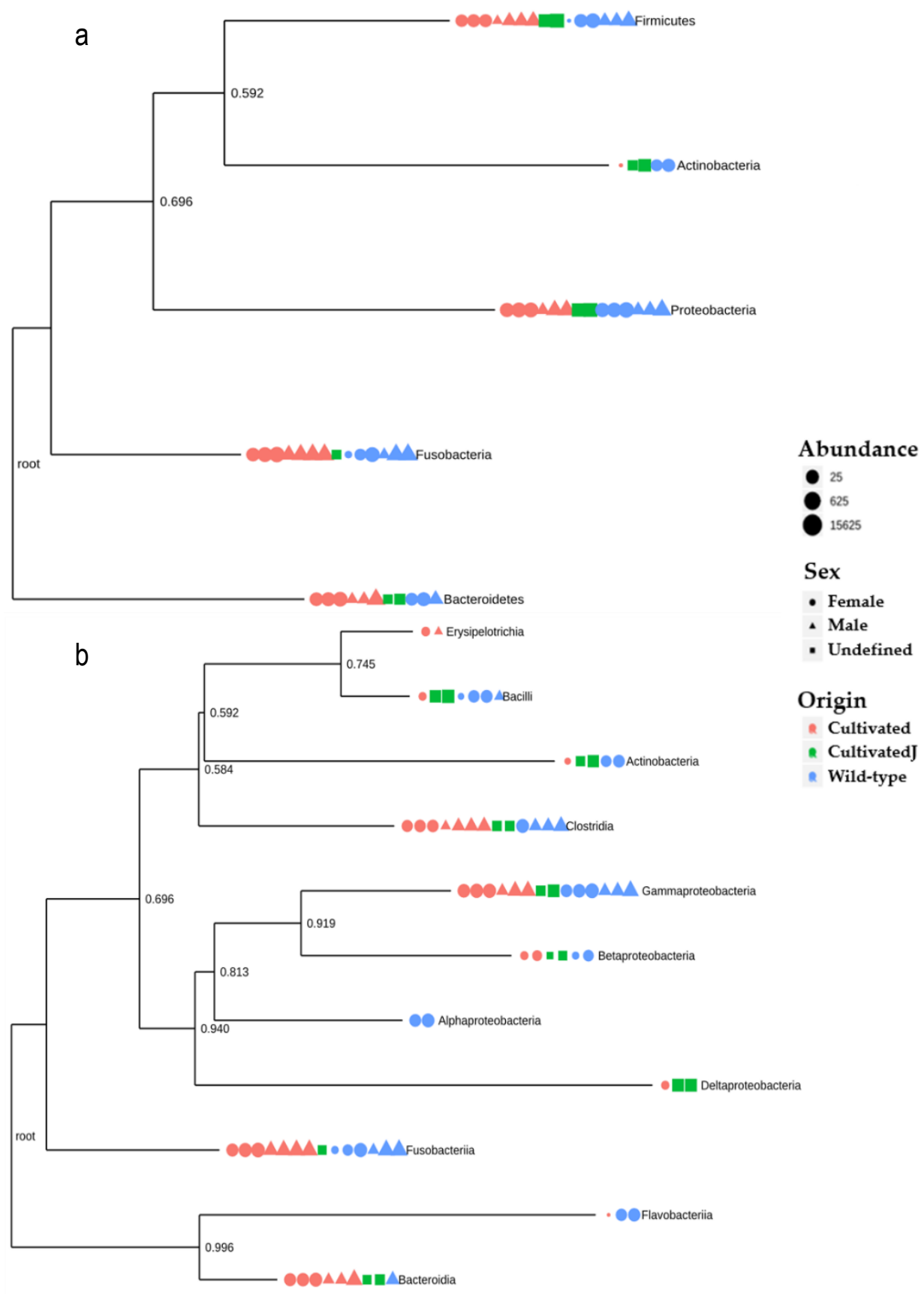

Figure 3. Taxonomic description by most abundant phylogenetic groups: a) phylum and b) class in the central microbiome of the gut tropical gars (Atractosteus tropicus), juveniles and adults, wild-type and cultivated.

integrate the core microbiome gut in adult A. tropicus. On the other hand, these nine species, identified by blue squares, are those that have probiotic potential.

\section{DISCUSSION}

We identified and compared the core microbiome and microbial diversity, respectively, in the gut of juveniles and adult Atractosteus tropicus by sex and origin. Pre- vious studies have shown that the fish gut hosts an estimated 107 to 1,011 bacteria per gram of intestinal content (Nayak, 2010). The bacterial colonizers in fishes gut include Proteobacteria, Fusobacteria, Firmicutes, Bacteroidetes, Actinobacteria, Clostridia, Bacilli, and Verrucomicrobia (Ringø et al., 2006; Desai et al., 2012; Li et al., 2013; Carda-Diéguez et al., 2014; Ingerslev et al., 2014a,b) with the first four being the most abundant, depending on environmental conditions 


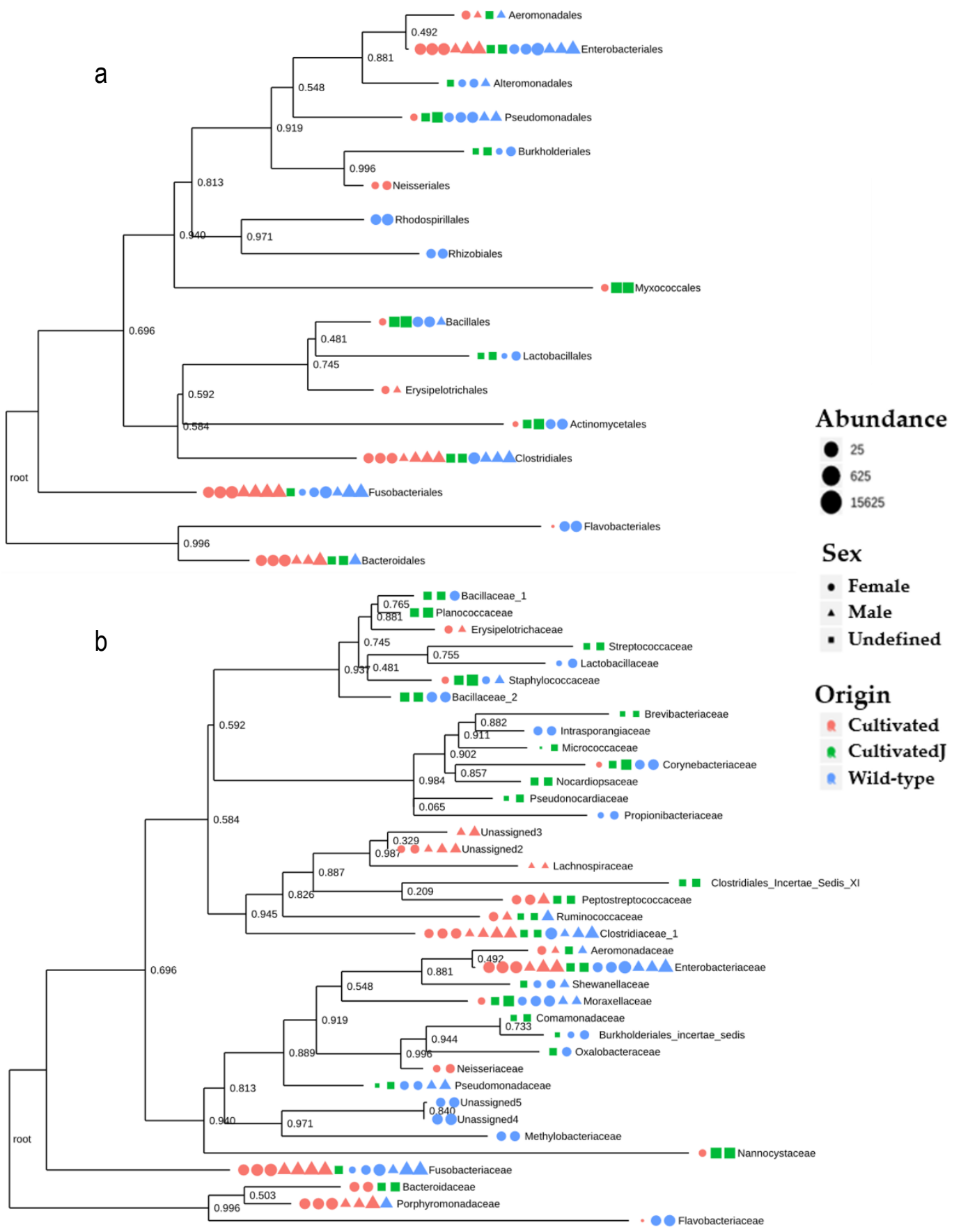

Figure 4. Taxonomic description by most abundant phylogenetic groups: a) order and b) family in the central microbiome of the gut tropical gars (Atractosteus tropicus), juveniles and adults, wild-type and cultivated.

and the host's diet (Wang et al., 2018). Almost all Fusobacteria, Proteobacteria, Firmicutes, Bacteroidetes, and Actinobacteria 16S rRNA sequences that we detect in GMBiot of the juvenile and adult A. tropicus (Fig. 2a, Table 3) belonged to the Cetobacterium, Serratia, Edwardsiella, Paludibacter, Clostridium sensu stricto, Staphylococcus, Plesiocystis, and Myroides genres (Fig. 2b, Table 2). The observed bacterial profiles in the gut of A. tropicus adult by sex and origin may reflect specific central microbiota, beyond the differences most likely attributable to feeding behavior. At the phylum level, almost $90 \%$ of the total bacterial abundance was classified into a total of four phyla. Among these phyla, Fusobacteria and Proteobacteria were dominant in the 17 A. tropicus samples by sex and origin (Figs. 2a-3a). In contrast, Firmicutes, Proteobacteria, and 


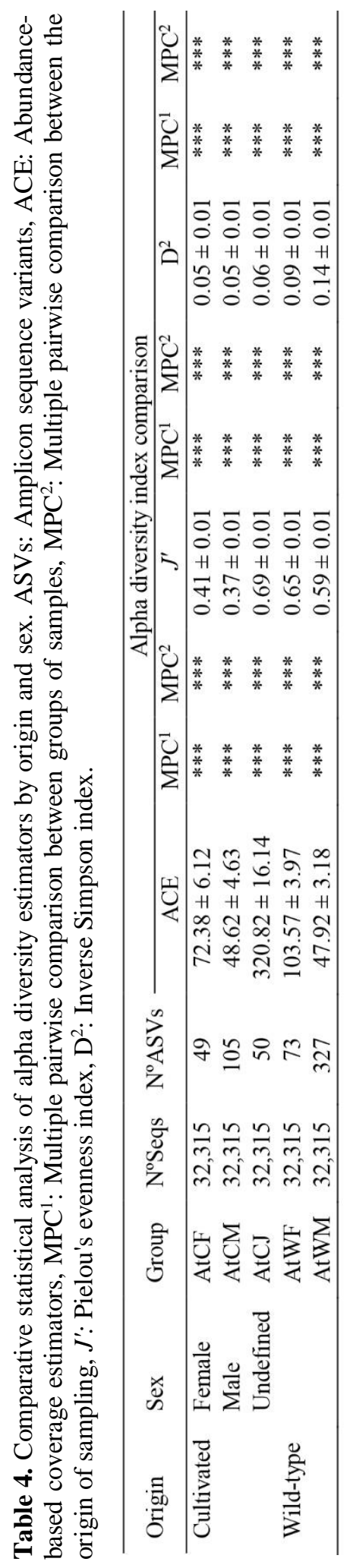

Bacteroidetes were identified as dominant phyla in the gut microbiota of the cultivated A. tropicus juvenile (Fig. 2a, Table 2). The inferred physiological roles of these dominant prokaryotes are related to the metabolism of carbohydrates and nitrogenous compounds (Kormas et al., 2014). Unlike the dominant microbiota of marine fish is facultative anaerobes, including Vibrio, Pseudomonas, Acinetobacter, Corynebacterium, Alteromonas, Flavobacterium and Micrococcus (Onarheim et al., 1994; Blanch et al., 1997; Verner-Jeffreys et al., 2003).

Alpha diversity results indicate the highest gut microbiota abundance and richness is found in cultivated juvenile and wild-type adult A. tropicus female, rather than adult wild-type males and the least gut microbiota abundance and richness is found in adult A. tropicus, cultivated females or males (Table 3). Ley et al. (2008) concluded that the gut microbiota of herbivorous mammals has an enormous richness and phylogenetic diversity, and both richness and phylogenetic diversity decreased among omnivores and decreased further among carnivores. We found the lowest richness and phylogenetic diversity (Table 3 ) in gut microbiomes from adults A. tropicus, which is defined as top piscivores (carnivores, e.g., cultivated female and male A. tropicus). Indeed, MacFarlane et al. (1986) observed that farm-raised fish had a simpler gut microbiota than their wild counterparts.

Likewise, our coefficients of UniFrac similarity or dissimilarity by PCoA ordination analysis, indicate gut microbiota of cultivated juvenile, and wild-type and cultivated A. tropicus adult are only similar to two wildtype adult samples and one cultivated adult. Also, dissimilarity by most of the wild-type and cultivated samples, but the cultivated juvenile is more significant than all the other organisms, particularly (Fig. 4). The PCoA revealed that gut bacterial communities from adult A. tropicus by origin formed different clusters. Cultivated and wild organisms formed distinct clusters in the PCoA space (Fig. 4), suggesting that the enrichment and diversity of gut microbiota are affected by the origin. This result is similar to the research of $\mathrm{Ni}$ et al. (2012) in that the origin and host phylogeny are entirely related to the composition of adult A. tropicus gut bacteria. Moreover, previous studies have shown that the microbiotic diversity content in all intestinal sections depends not only on the fish size but also on their age (Moran et al., 2005; Cantas et al., 2012; Bolnick et al., 2014; Clements et al., 2014), such as the case of cultivated A. tropicus juvenile (sexually immature fish).

Numerous studies have been built on these results, demonstrating that many species of herbivores and omnivores fishes contain diverse intestinal communities 


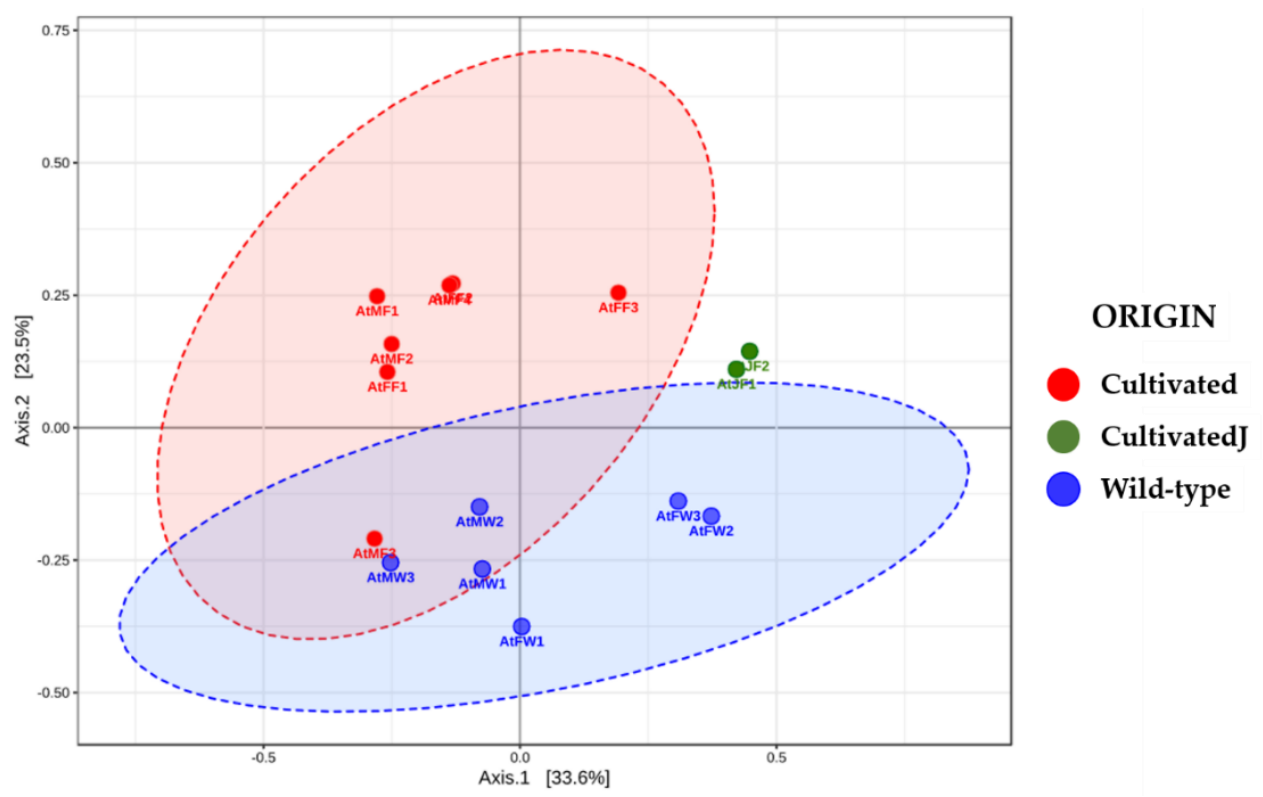

Figure 5. Similarity or dissimilarity coefficients of Unweighted UniFrac distances (UniFrac) by PCoA ordination analysis of the microbiota in Atractosteus tropicus. The green circles represent the cultivated juvenile, and blue and red circles correspond to wild and cultivated adult, respectively.

Table 5. Multiple pairwise comparison adonis test (post-hoc) of the different families (groups) of Atractosteus tropicus) specimens.

\begin{tabular}{cllccccc}
\hline \multirow{2}{*}{ Family } & \multicolumn{2}{c}{ Group } & Sample size & Permutations & pseudo-F & $P$-value & $q$-value \\
\cline { 2 - 8 } & \multicolumn{1}{c}{1} & & 2 & 999 & 4.31 & 0.02 & 0.03 \\
\hline 1 & Cultivated adults & Cultivated juveniles & 9 & 999 & 2.32 & 0.02 & 0.03 \\
2 & Cultivated adults & Wild-type & 13 & 999 & 2.34 & 0.04 & 0.04 \\
3 & Cultivated juveniles & Wild-type & 8 & & & \\
\hline
\end{tabular}

nities (Rimmer \& Wiebe, 1987; Clements et al., 1989; Clements, 1991, 1997; Martínez-Díaz \& Pérez-España, 1999; Ray et al., 2012;) and that herbivorous and detritivorous fish species harbor distinctive microbial populations (Clements et al., 2014). Feeding habits are also an essential factor that generally influences the microbial diversity in the fish core gut microbiome (CGMBiom), displaying a higher diversity in the following order: carnivores $>$ omnivores $>$ herbivores (Ward et al., 2009; Larsen et al., 2014; Li et al., 2014a,b; Miyake et al., 2015; Liu et al., 2016). He et al. (2013) revealed that the herbivorous carp (Ctenopharyngodon idellus) reported a wider variety of bacterial species than the dark carnivorous carps and Gibel (Carassius gibelio), which are exclusively omnivorous, and also the sea bream, under the same culture conditions. We also identify this same trend widely in the CGMBiom in A. tropicus juvenile and adult, by sex and origin, because although these are omnivores, they prefer carnivorous habits (Méndez-
Marin et al., 2012) (Fig. 5a). At the sex level, we observed that the core microbiome is more diverse in female organisms, and particularly in wild-type organisms (Figs. 5b, 6a-b). In this sense, we can suggest that the feeding type of juveniles cultivated at the farmed and used in this work is more omnivore or herbivore than a carnivore.

More recent sequence-based approaches show that fish hindgut microbial communities much more closely resemble those of mammals than environmental microbial communities (Fidopiastis et al., 2006; Sullam et al., 2012), especially in the prevalence of Proteobacteria, Firmicutes and Bacteroidetes (Clements et al., 2007; Smriga et al., 2010; Sullam et al., 2012; Ye et al., 2014). These findings indicate that fish, like other vertebrates, harbor specific gastrointestinal communities (Clements et al., 2014). We identified Proteobacteria as the most dominant phylum and the second dominant phylum in CGMBiom of the adult and cultivated A. tropicus juvenile, respectively (Fig. 2a). 


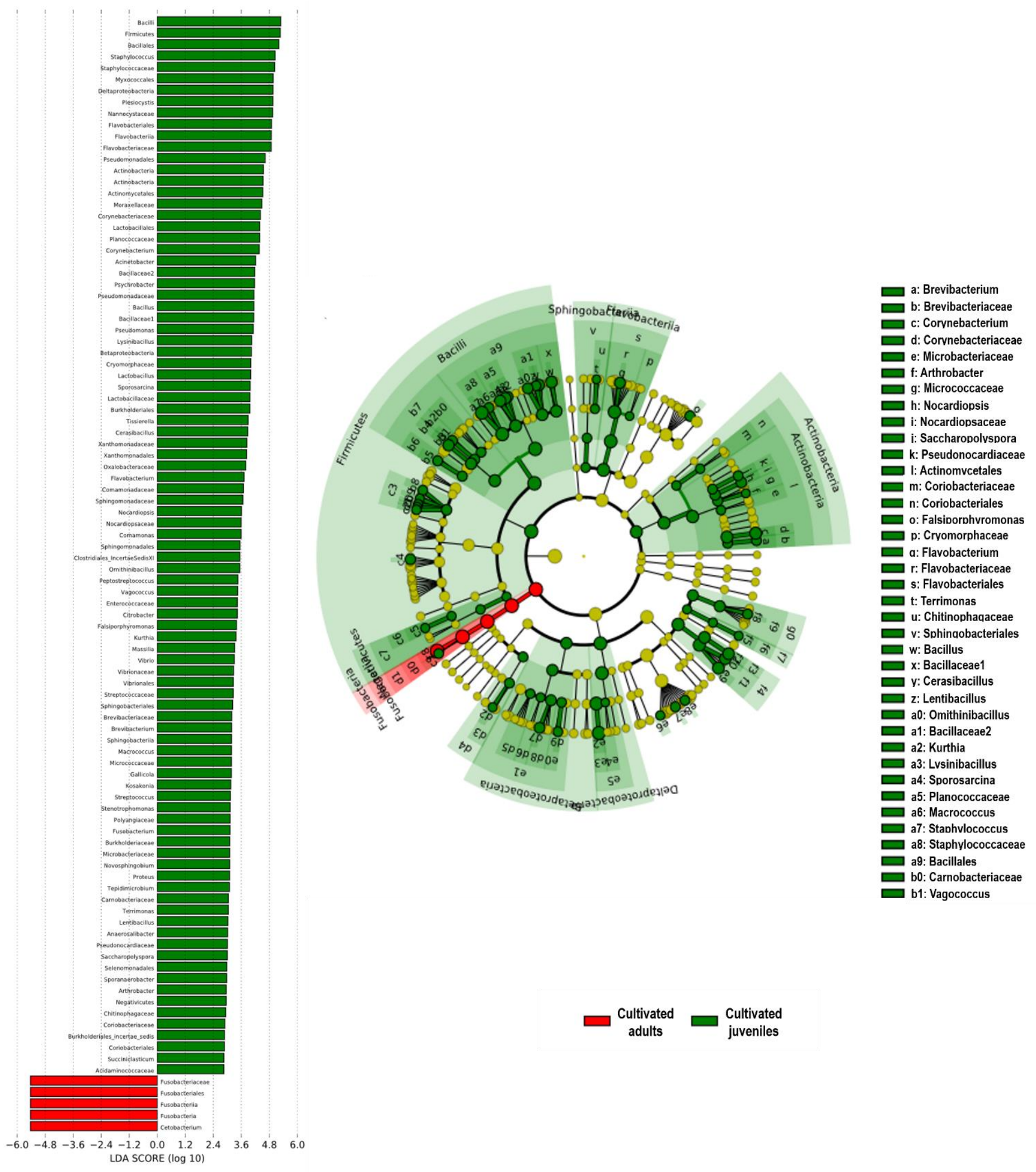

Figure 6. LEfSe Biomarkers identification analysis with LDA score histogram of the microbiota composition in Atractosteus tropicus. Comparison among cultivated juvenile and adult organisms. Highlighting that, at the phylum level, Firmicutes are dominant in cultivated juvenile organisms, whereas Fusobacteria is dominant in cultivated adult organisms. Red and green colors indicate cultivated juveniles and adult organisms, respectively. 

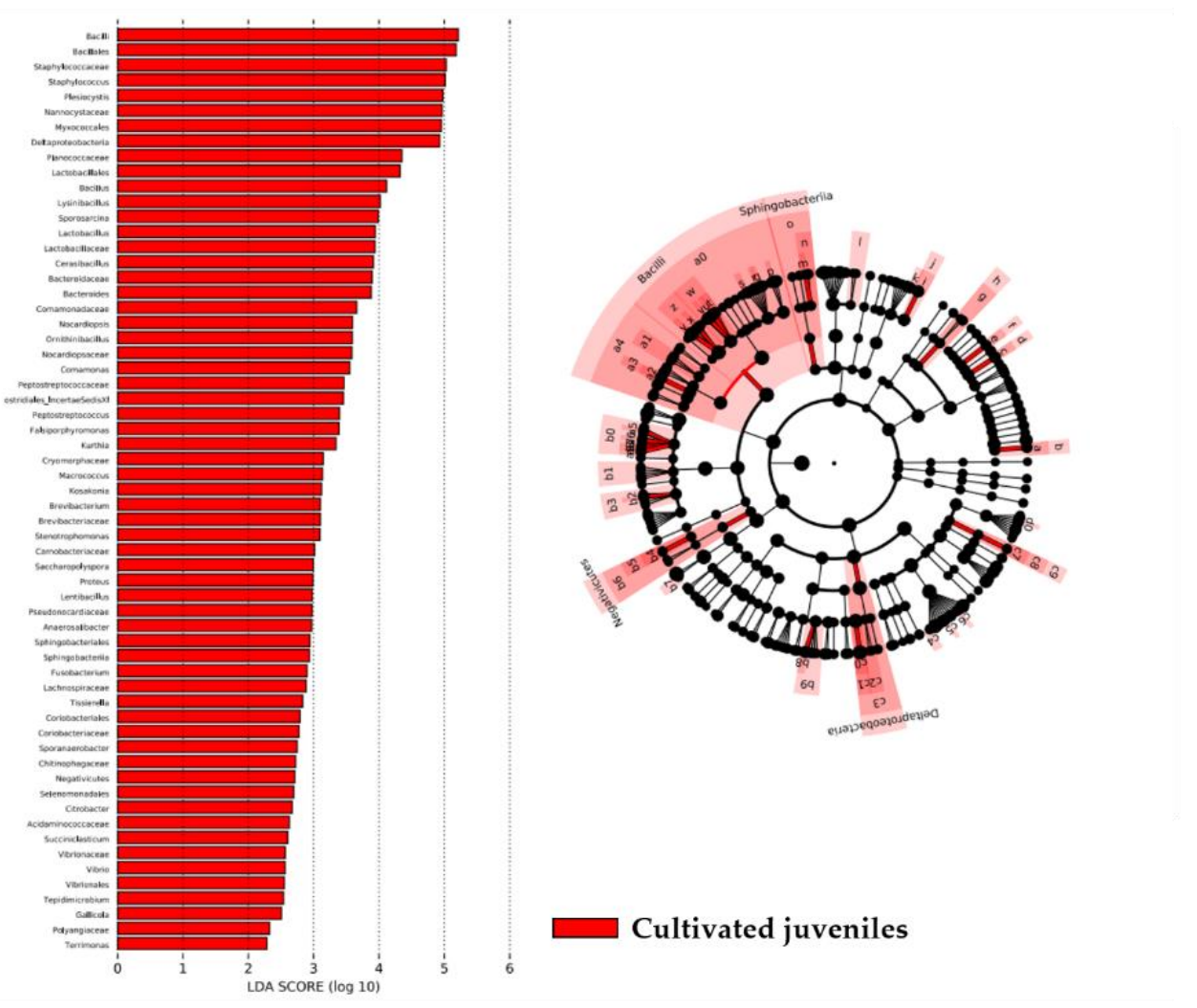

$\square$ Cultivated juveniles

Figure 7. LEfSe Biomarkers identification analysis with LDA score histogram of microbiota in Atractosteus tropicus composition in cultivated juvenile organisms. We show statistically of gut microbiota abundance in A. tropicus gut of the cultivated juvenile organisms. Red color indicates cultivated juveniles.

According to Rudi et al. (2018), Proteobacteria phylum is very characteristic in wild-type fish and denotes of a high-fat diet.

We identified Fusobacteria as the most dominant phylum and the second dominant phylum in the gut of the cultivated $A$. tropicus juvenile and male adult (wild and cultivated), respectively (Fig. 2a). A few studies have shown Fusobacteria as dominant members of the gut microbiota of freshwater fishes (Van Kessel et al., 2011; Di Maiuta et al., 2013). Fusobacteria is anaerobic, Gram-negative bacilli that produce butyrate

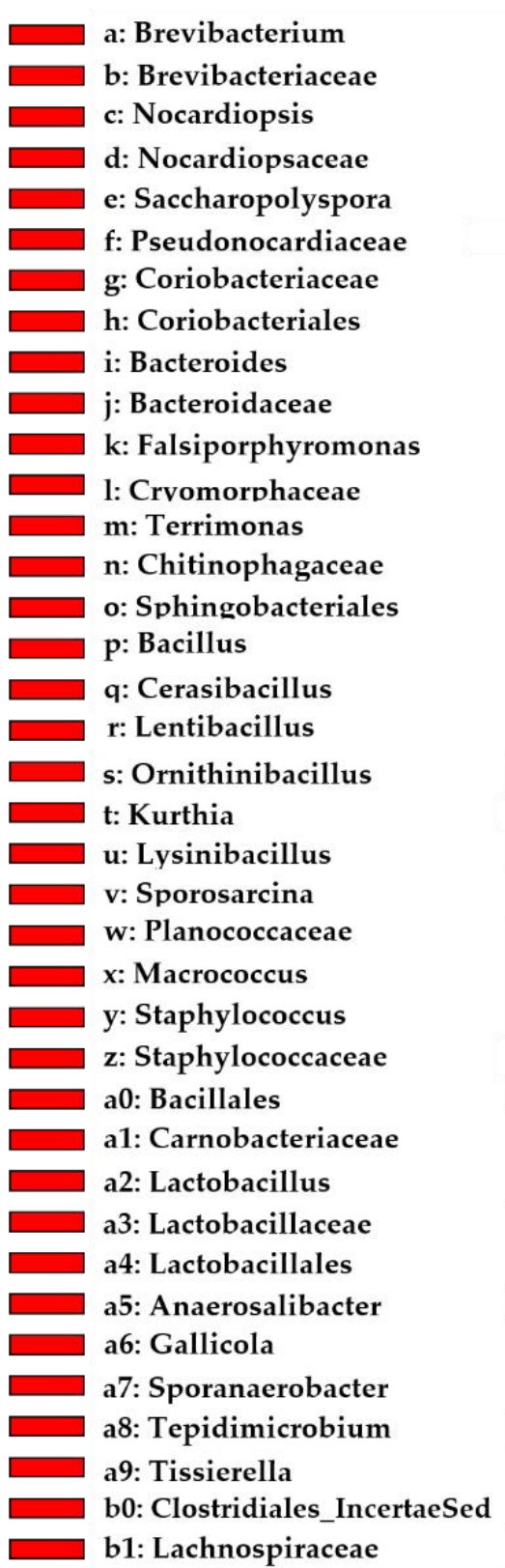



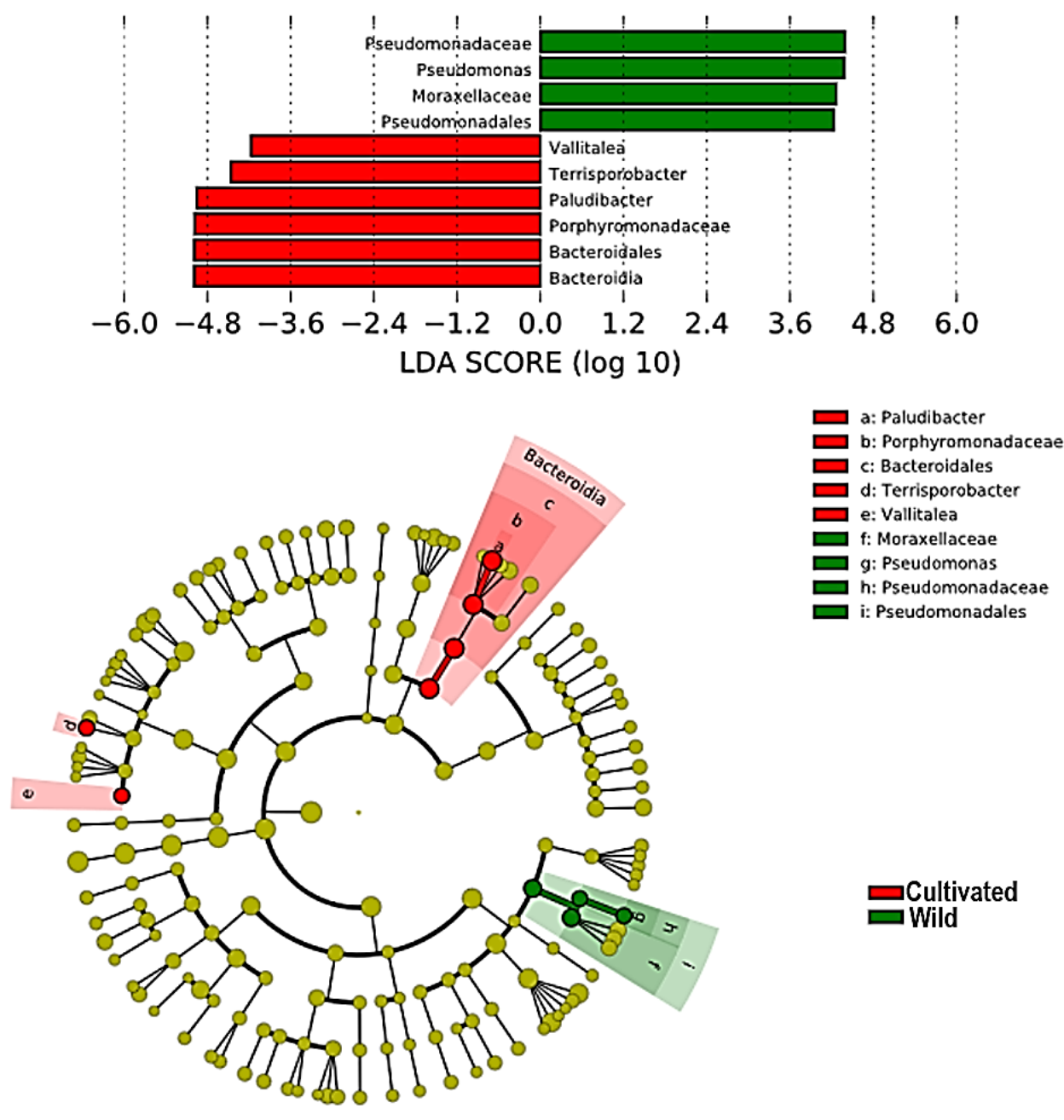

Figure 8. LEfSe Biomarkers identification analysis with LDA score histogram of microbiota in adults Atractosteus tropicus composition. Comparison between wild-type and cultivated organisms. Both show statistically significant differences depending on the origin. Red and green colors indicate cultivated and wild-type adult organisms.

et al., 2009;). This fatty acid has been found in the gut of herbivorous and omnivorous fishes only (Clements et al., 1994; Clements \& Choat, 1995). Nuez-Ortin et al. (2012) demonstrated that the ability of butyric acid to inhibit potential freshwater fish pathogens and sodium butyrate is currently sold as a food additive to promote fish health and growth. However, trials using blends of sodium butyrate and other additives have not proven beneficial (Owen et al., 2006; Gao et al., 2011).

OTUs sequences of the Cetobacterium genus were identified as dominant mainly in the gut microbiome of A. tropicus adult, wild and cultivated male fish. Cetobacterium genus is widely recognized in freshwater and warm water fish species (Tsuchiya et al., 2008; Larsen et al., 2014; Li et al., 2017). Cetobacterium genus members' presence can perform fermentative metabolism of peptides and carbohydrates and produce vitamin B12 (cobalamin) (Larsen et al., 2014). Cetobacterium and Bacteroides were reported as significant producers of the vitamin B12 in the intestine (Tsuchiya et al., 2008; Vogiatzoglou et al., 2009) and they were the dominant genera in grass carp's intestine, with the abundance of more than 50\% (Li et al., 2015a). Animals, plants, and fungi are incapable of cobalamin production, and it is the only vitamin that is exclusively produced by microorganisms, particularly by anaerobes (Roth et al., 1996; Martens et al., 2002; Smith et al., 2007). Qi et al. (2017) showed that different concentrations of ammonia would affect the abundance of Bacteroides and Cetobacterium in gut fish, and the higher the concentration, the lower the abundance.

The majority of the most abundant OTUs present in CGMBiom of the cultivated A. tropicus juvenile samples were from the Staphylococcus $(2.62 \%)$, 
Plesiocystis (2.56\%) and Myroides (2.36\%) genera. Staphylococcus is the only genus exclusive for the distal gut digesta of fish fed a median carbohydrate and protein diet (Villasante et al., 2019) or is associated with the gut immune system, which is known as gutassociated lymphoid tissues (GALT, Nayak, 2010). Plesiocystis is a genus of Myxobacteria and a monotypic taxon containing only its type species, Plesiocystis pacifica. Both the genus and the species were first described in 2003, based on two strains isolated from samples collected from the Pacific coast of Japan (Iizuka et al., 2003). They have unique cellular metabolism featuring, among other characteristics, partially saturated menaquinone $[\mathrm{MK}-8(\mathrm{H} 2)]$ or vitamin $\mathrm{K} 2$, polyunsaturated fatty acid production, and an absence of hydroxy fatty acids. Like typical myxobacteria, they have high GC content (Iizuka et al., 2003). In nature, Myxobacteria appears to be ubiquitous and diverse, and are not just terrestrial but found in marine, estuarine, and a variety of other saline ecosystems. Metagenomic analyses indicate that the marine myxobacteria identified to date occupy only a small portion of the potential Nannocystineae phylogenetic tree (García et al., 2018). Myroides strains have been identified in clinical samples, marine environments, freshwater fish and insect gut (Holmes et al., 1977; Gonzalez et al., 2000; Spiteller et al., 2000; Yoon et al., 2006; Zhang et al., 2008), but are not components of the normal human microbioma (Maraki et al., 2012). Myroides genus is a member of the Bacteroidetes and Flavobacteriaceae, phylum and family, respectively. JS-08T strain belonging to the genus Myroides contains other menaquinone-6 (MK-6) type or vitamin $\mathrm{K} 2$, as the predominant menaquinone, and dominant fatty acids, such as iso-C15: 0 , iso-C17: 0 3-OH and a summarized characteristic that consists of iso-C15: $02-\mathrm{OH}$ or C16: 1v7c. The G + C DNA content of this strain is $34.2 \mathrm{~mol} \%$ (Cho et al., 2011). Vitamin K plays a vital role in blood coagulation and bone mineralization in fish, but the suggested minimum requirement varies considerably depending on the vitamin $\mathrm{K}$ source used. Vitamin $\mathrm{K}$ deficiency is characterized by mortality, anemia, increased blood clotting time, and histopathological changes in liver and gills (Krossøy et al., 2011). In the case of $M$. odoratimimus can be classified as a "strong biofilmproducer" (Stepanović et al., 2007) and their use as a probiotic potential in certain juvenile fish turns out to be interesting (Villamil-Diaz \& Esguerra-Rodríguez, 2017), this suggests that a vast diversity of species is unexplored.

We detected OTUs of Deinococcus-Thermus bacterial phyla to be non-dominant $(0.003 \pm 0.006 \mathrm{SD})$ in the gut microbiome of A. tropicus adult, wild-type males only. However, Deinococcus-Thermus species are known for their resistance to extreme stresses, such as radiation, oxidation, desiccation, and high temperature (Li et al., 2015b). The deeply branching Deinococcus-Thermus lineage is recognized as one of the most extremophilic phyla of bacteria (Theodorakopoulos et al., 2013). Sequence information from Deinococcus-Thermus phylum is presently available for only a limited number of species. However, the sequenced genomes include species from both the leading families (i.e., Deinococcaceae and Thermaceae) within this phylum (Griffiths \& Gupta, 2007). In recent years, researchers have begun using Deinococcus spp. in biotechnologies and bioremediation due to their specific ability to grow and express novel engineered functions. More recently, the sequencing of several Deinococcus spp.

Furthermore, comparative genomic analysis has provided new insight into the potential of this genus. Features such as the accumulation of genes encoding cell cleaning systems that eliminate organic and inorganic cell toxic components are widespread among Deinococcus spp. Other features, such as the ability to degrade and metabolize sugars and polymeric sugars, make Deinococcus spp. an attractive alternative for use in industrial biotechnology (Gerber et al., 2015). That is why their functional role in the gut of A. tropicus adults deserves further research.

Bacteroidetes phylum has a low relative abundance in the gut microbiota of $A$. tropicus adult, cultivated and wild-type, and very low relative abundance in the gut of cultivated A. tropicus juvenile (Fig. 2a, Table 2). Despite, this phylum is composed of three large classes of Gram-negative, non-spore-forming, anaerobic or aerobic, and rod-shaped bacteria that are widely distributed in the environment, including in soil, sediments, and seawater, as well as in the guts and on the skin of animals (Ley et al., 2008). Likewise, a large part of the proteins synthesized by the genome of Bacteroides, a genus of Bacteroidetes, can break down polysaccharides and metabolize their sugars, playing a fundamental role in the degradation of complex molecules in the gut of the host. Their ability to harvest alternative energy sources from food could allow Bacteroides to be more competitive than other bacteria in CGMBiom of fish during starvation stage (Xu et al., 2003; Xia et al., 2014).

We identified Clostridium sensu stricto genus sequences in the GMBiom of A. tropicus adult, wildtype males only. This genus has also been identified in GMBiom of carp fish (Li et al., 2015a). The members of the genus Clostridium sensu stricto are dominant in the intestinal microbiota of grass carp (Ctenopharyngodon idellus) and are also versatile in their ability 


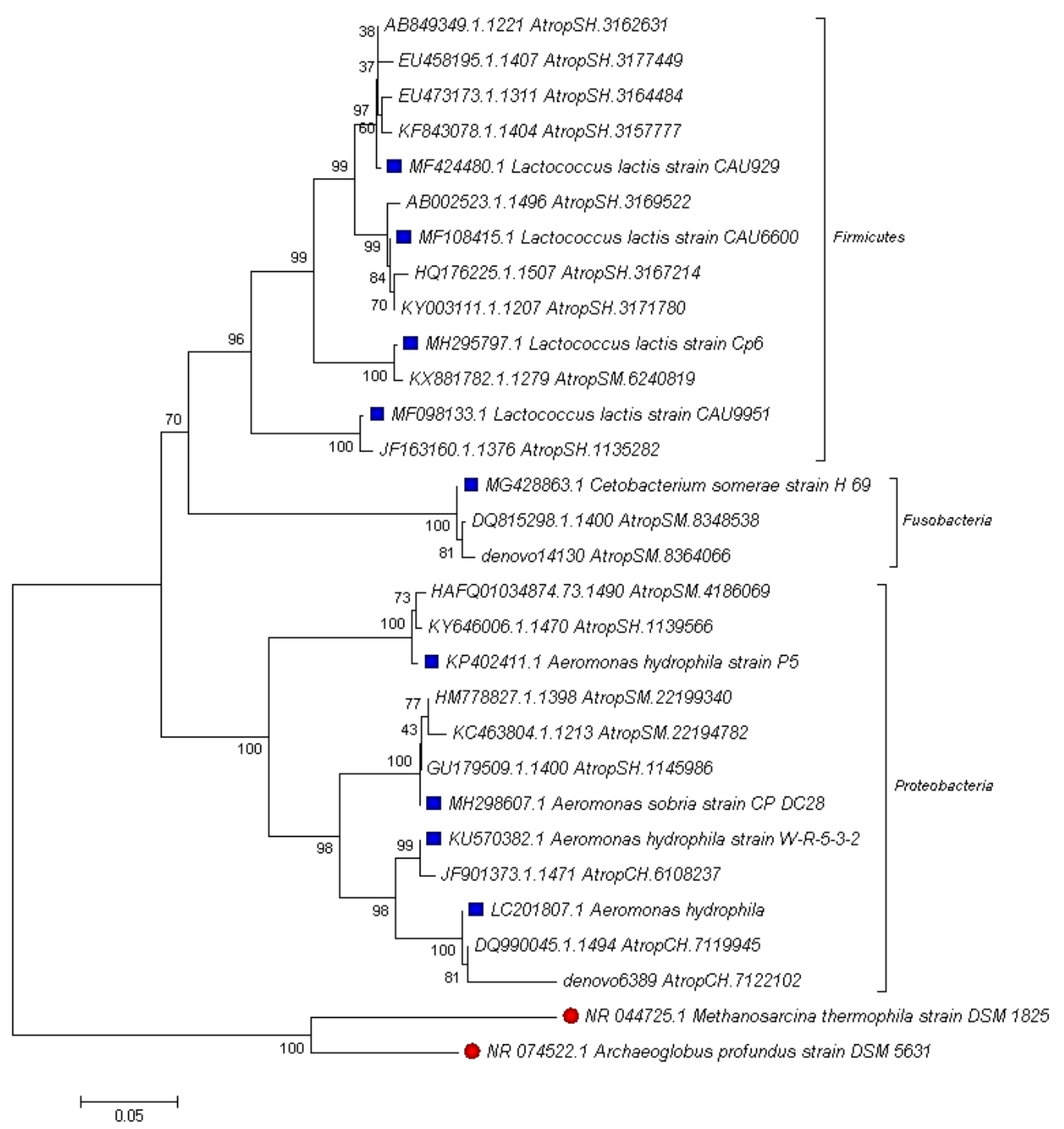

Figure 9. Phylogenetic tree from the rRNA 16S gene constructed of some organisms found in the literature with probiotic potential in fish (see Table 1). Red circles and blue squares represent outgroup and reference sequences, respectively.

to utilize various polysaccharides, such as cellulose, xylan, and hemicelluloses, which constitute the significant part of vegetal fibers (Uffen, 1997; Uz \& Ogram, 2006; Li et al., 2015a). Others also include not only species with saccharolytic and fiber-fermenting activities but also proteolytic species (Lubbs et al., 2009; Pikuta et al., 2009; Li et al., 2015a).

Serratia, Edwardsiella, Plesiomonas, and Reyranella are genera belonging to the Enterobacteriaceae family and the Proteobacteria phylum. These isolated bacterial species are facultative pathogens for fish and humans and may be isolated from fish without apparent symptoms of the disease (Walczak et al., 2017). Serratia produces serrawettin that acts as a wetting agent to reduce the surface tension of the environment
(Chan et al., 2013). Edwardsiella has been isolated from tortoises (Iveson, 1971), crocodiles (Iveson, 1971), aquarium water (Bartlett \& Lior, 1977), and seagull roosting areas (Berg \& Anderson, 1972). Edwardsiella was isolated on several occasions during the examination of dressed catfish for Salmonella (Wyatt et al., 1979). This report provides information on the isolation, identification, and incidence of Edwardsiella in freshwater catfish and their environment. There are many unanswered questions regarding their importance in freshwater fish. Liu et al. (2015) reported the pathogenicity of Plesiomonas shigelloides to fish. $P$. shigelloides can occur as natural intestinal flora of fish, but in case of stress conditions, the following symptoms are observed: darkening of the 
body, hemorrhaging, fin rotting, ascitic fluid in the abdominal cavity, and lesions in internal organs. Phylogenetically, the Reyranella genus has an evolutionary lineage within the family Rhodospirillaceae in the class Alphaproteobacteria. The type species Reyranella massiliensis was initially identified by Pagnier et al. (2011). Subsequently, Kim et al. (2013) amended several characteristics (e.g., nitrate reduction, respiratory quinone information) into the genus description, and more recently, Cui et al. (2017) found that reduction of nitrate to nitrite is variable, the predominant isoprenoid quinone is ubiquinone-10 (Q10), major polar lipids are PME, DPG, PG, PE, and one unknown amino lipid. We detected these genera mainly in the gut microbiome of A. tropicus adult, wild-type females, and cultivated females and male fish (Figs. $2 b$, $3 b)$. We consider that, although commonly known for their ability to cause deadly infectious diseases, this is a population of bacteria (identified as normal flora of adult $A$. tropicus), which despite symbiotically living on and between wild-type females and cultivated females and males of $A$. tropicus adult, really has a positive impact on host survival (Figs. 2b, 3b).

The Paludibacter genus has been found exclusively in African microbiota, probably due to their increased fitness to grow on polysaccharides abundant in xylan or cellulose diets (De Filippo et al., 2010; Thomas et al., 2011). We identified OTUs of the Paludibacter genus in the core gut microbiome of A. tropicus adult, in females and males cultivated fish, only (Fig. 2b).

In phylogenetic trees reconstruction (Fig. 9) and according to Table 1, we identified the species Lactococcus lactis strains CAU929 and CAU6600, Cp6 and CAU9951, Cetobacterium strain H69, Aeromonas hydrophila strains P5 and WR-5-3- 2, Aeromonas sobria strain CP DC28 and Aeromonas hydrophila with probiotic potential within the three dominant phyla in core gut microbiome of A. tropicus adult.

Considering the above, fish CGMBiom can influence nutrition, growth, reproduction, general population dynamics, and the host's vulnerability to diseases, thus supporting a crucial role in aquaculture practice (Ghanbari et al., 2015). Current DNA sequencing technologies and bioinformatic analysis have contributed towards a deeper understanding of the complex microbial communities associated to diverse habitats, including CGMBiom of fish in response to a variety of factors affecting the host, including temperature variations, salinity, growth stage, digestive physiology and feeding strategy (Cahill, 1990; Jammal et al., 2017). The concept' core microbiota' referred to a set of abundant microbial lineages that are shared by all individuals from the same species (Wong et al., 2013). The concept of CGMBiom has been explored both in mammalian host's context and in freshwater fish (Turnbaugh et al., 2009; Nam et al., 2011; Roeselers et al., 2011; Wu et al., 2012; Wong et al., 2013.

\section{CONCLUSIONS}

Greater diversity and richness in Atractosteus tropicus adult gut microbiome of wild than cultivated and $A$. tropicus gut microbiome of juvenile and adult wild females were higher than wild and cultivated males' adults, at the genus level, respectively. The core gut microbiome of A. tropicus juvenile and adult are constituted by Proteobacteria, Fusobacteria, Firmicutes, and Bacteroidetes phyla. Further, A. tropicus adults have adapted to the environment and diet due to their high saccharolytic capacity, fiber fermentation, and starvation activities. Also, it has been identified in A. tropicus juvenile gut microbiome the Staphylococcus, Plesiocystis, and Myroides genera. Likewise, Deinococcus-Thermus bacterial phyla and Clostridium sensu stricto genus were only identified in A. tropicus adult gut microbiome of the wild-type males, of great interest at biotechnology. In phylogenetic trees reconstruction, Lactococcus lactis strains CAU929, CAU6600, Cp6 and CAU9951, Cetobacterium strain H69, Aeromonas hydrophila strains P5 and WR-5-3-2, Aeromonas sobria strain CP DC28 and Aeromonas hydrophila were identified, which have the probiotic potential within the three dominant phyla in core gut microbiome of $A$. tropicus adult. The CGMBiom of $A$. tropicus, due to essential roles in the immune system modulation, the intestinal epithelium proliferation, and the regulation of the dietary energy intake, is increasingly regarded as an integral component of the host. Understanding the factors that influence the composition of these microbial communities is essential to health management, and the application to aquatic animals still requires more investigation.

\section{ACKNOWLEDGMENTS}

The authors thank the Mexican National Council of Science and Technology for the postgraduate studies thesis scholarship and the mixed scholarship granted to carry out the research internship at the University of Valencia (Spain). This research received external funding from the Mexican National Council of Science and Technology "Strengthening of the Master's Degree in Environmental Sciences for its Permanence in the National Register of Quality Graduates of CONACYT" Reg. No. TAB-2014-C29-245836 and the Project "Estudio de la fisiología digestiva en larvas y juveniles de pejelagarto (Atractosteus tropicus) con base en técnicas histológicas, bioquímicas y moleculares" Reg. No. CB-2016-01-282765. 


\section{REFERENCES}

Aitchison, J. 1982. The statistical analysis of compositional data. Journal of the Royal Statistical Society B: Methodological, 44(2): 139-160. doi: 10.1007/978-94009-4109-0

Al-Harbi, A.H. \& Uddin, N. 2005. Bacterial diversity of tilapia (Oreochromis niloticus) cultured in brackish water in Saudi Arabia. Aquaculture, 250(3-4): 566572.

Andoh, A., Bamba, T. \& Sasaki, M. 1999. Physiological and anti-inflammatory roles of dietary fiber and butyrate in intestinal functions. Journal of Parenteral and Enteral Nutrition, 23: 70-73.

Austin, B. \& Austin, D.A. 2016. Bacterial fish pathogens: disease of farmed and wild fish. Springer, New York.

Avila-Villa, L.A., Martínez-Porchas, M., Gollas-Galván, T., López-Elías, J.A., Mercado, L., Murguia-López, Á. et al. 2011. Evaluation of different microalgae species and Artemia (Artemia franciscana) as possible vectors of necrotizing hepatopancreatitis bacteria. Aquaculture, 318(3-4): 273-276.

Bartlett, K.H. \& Lior, H. 1977. Small pet aquarium frogs as a source of Salmonella. Applied and Environmental Microbiology, 33(5): 1026-1029.

Bennett, K.W. \& Eley, A. 1993. Fusobacteria: new taxonomy and related diseases. Journal of Medical Microbiology, 39(4): 246-254.

Berg, R.W. \& Anderson, A.W. 1972. Salmonellae and Edwardsiella tarda in gull feces: a source of contamination in fish processing plants. Applied Microbiology, 24(3): 501-503.

Blanch, A.R., Alsina, M., Simon, M. \& Jofre, J. 1997. Determination of bacteria associated with reared turbot (Scophthalmus maximus) larvae. Journal of Applied Microbiology, 82(6): 729-734.

Bolnick, D.I., Snowberg, L.K., Hirsch, P.E., Lauber, C.L. Knight, R., Caporaso, J.G. \& Svanbäck, R. 2014. Individuals' diet diversity influences gut microbial diversity in two freshwater fish (threespine stickleback and Eurasian perch). Ecology Letters, 17(8): 979-987. doi: 10.1111/ele.12301

Bondad-Reantaso, M.G., Subasinghe, R.P., Arthur, J.R., Ogawa, K., Chinabut, S., Adlard, R. \& Shariff, M. 2005. Disease and health management in Asian aquaculture. Veterinary Parasitology, 132(3-4): 249272.

Bussing, W.A. 1987. Peces de las aguas continentales de Costa Rica. Editorial Universidad de Costa Rica, San José

Cahill, M.M. 1990. Bacterial flora of fishes: a review. Microbial Ecology, 19(1): 21-41. doi: 10.1007/BF 02015051
Callahan, B.J., McMurdie, P.J., Rosen, M.J., Han, A.W., Johnson, A.J.A. \& Holmes, S.P. 2016. DADA2: highresolution sample inference from Illumina amplicon data. Nature Methods, 13(7): 581. doi: 10.1038/ nmeth.3869

Cantas, L., Sørby, J.R.T., Aleström, P. \& Sørum, H. 2012. Culturable gut microbiota diversity in zebrafish. Zebrafish, 9(1): 26-37. doi: 10.1089/zeb.2011.0712

Caporaso, J.G., Lauber, C.L., Walters, W.A., Berg-Lyons, D., Lozupone, C.A., Turnbaugh, P.J., et al. 2011. Global patterns of 16S rRNA diversity at a depth of millions of sequences per sample. Proceedings of the National Academy of Sciences, 108(1): 4516-4522.

Carda-Diéguez, M., Mira, A. \& Fouz, B. 2014. Pyrosequencing survey of intestinal microbiota diversity in cultured sea bass (Dicentrarchus labrax) fed functional diets. FEMS Microbiology Ecology, 87(2): 451-459.

Chan, X.Y., Chang, C.Y., Hong, K.W., Tee, K.K., Yin, W.F. \& Chan, K.G. 2013. Insights of biosurfactant producing Serratia marcescens strain W2.3 isolated from diseased tilapia fish: a draft genome analysis. Gut Pathogens, 5(1): 29.

Cho, S.-H., Chae, S.-H., Im, W.-T. \& Kim, S.B. 2011. Myroides marinus sp. nov., a member of the family Flavobacteriaceae, isolated from seawater. International Journal of Systematic and Evolutionary Microbiology, 61(4): 938-941.

Clements, K.D. 1991. Endosymbiotic communities of two herbivorous labroid fishes, Odax cyanomelas and $O$. pullus. Marine Biology, 109(2): 223-229.

Clements, K.D. 1997. Fermentation and gastrointestinal microorganisms in fishes. Springer, Chapman \& Hall, New York.

Clements, K.D. \& Choat, J.H. 1995. Fermentation in tropical marine herbivorous fishes. Physiological Zoology, 68(3): 355-378.

Clements, K.D., Gleeson, V.P. \& Slaytor, M. 1994. Shortchain fatty acid metabolism in temperate marine herbivorous fish. Journal of Comparative Physiology B. Biochemical, Systems, and Environmental Physiology, 164(5): 372-377.

Clements, K., Sutton, D. \& Choat, J. 1989. Occurrence and characteristics of unusual protistan symbionts from surgeonfishes (Acanthuridae) of the Great Barrier Reef, Australia. Marine Biology, 102(3): 403412.

Clements, K.D., Angert, E.R., Montgomery, W.L. \& Choat, J.H. 2014. Intestinal microbiota in fishes: what's known and what's not. Molecular Ecology, 23(8): 1891-1898. doi: 10.1111/mec.12699

Clements, K.D., Pasch, I.B. Y., Moran, D. \& Turner, S. J. 2007. Clostridia dominate 16S rRNA gene libraries prepared from the hindgut of temperate marine 
herbivorous fishes. Marine Biology, 150(6): 14311440. doi: 10.1007/s00227-006-0443-9

Collinder, E., Björnhag, G., Cardona, M., Norin, E., Rehbinder, C. \& Midtvedt, T. 2003. Gastrointestinal host-microbial interactions in mammals and fish: comparative studies in man, mice, rats, pigs, horses, cows, elks, reindeers, salmon, and cod. Microbial Ecology in Health and Disease, 15(2-3): 66-78.

Cui, Y., Chun, S.-J., Ko, S.-R., Lee, H.-G., Srivastava, A., Oh, H.-M. \& Ahn, C.-Y. 2017. Reyranella aquatilis sp. nov., an alphaproteobacterium isolated from a eutrophic lake. International Journal of Systematic and Evolutionary Microbiology, 67(9): 3496-3500. doi: 10.1099/ijsem.0.00215

D'Auria, G., Artacho, A., Rojas, R., Bautista, J., Méndez, R., Gamboa, M. \& Gómez-Cruz, R. 2018. Metagenomics of bacterial diversity in Villa Luz caves with sulfur water springs. Genes, 9(1): 55. doi: 10.3390/ genes 9010055

De Filippo, C., Cavalieri, D., Di Paola, M., Ramazzotti, M., Poullet, J.B., Massart, S. \& Lionetti, P. 2010. Impact of diet in shaping gut microbiota revealed by a comparative study in children from Europe and rural Africa. Proceedings of the National Academy of Sciences, 107(33): 14691-14696.

Desai, A.R., Links, M.G., Collins, S.A., Mansfield, G.S., Drew, M.D., Van Kessel, A.G. \& Hill, J.E. 2012. Effects of plant-based diets on the distal gut microbiome of rainbow trout (Oncorhynchus mykiss). Aquaculture, 350: 134-142.

Di Maiuta, N., Schwarzentruber, P., Schenker, M. \& Schoelkopf, J. 2013. Microbial population dynamics in the faeces of wood-eating loricariid catfishes. Letters in Applied Microbiology, 56(6): 401-407.

Fidopiastis, P.M., Bezdek, D.J., Horn, M.H. \& Kandel, J.S. 2006. Characterizing the resident, fermentative microbial consortium in the hindgut of the temperatezone herbivorous fish, Hermosilla azurea (Teleostei: Kyphosidae). Marine Biology, 148(3): 631-642.

Flores-Nava, A. \& Brown, A. 2010. Peces nativos de agua dulce de América del Sur de interés para la acuicultura: una síntesis del estado de desarrollo tecnológico de su cultivo. Food \& Agriculture Organization, Fisheries Department, ONU, New York.

Frías-Quintana, C.A., Márquez-Couturier, G., AlvarezGonzález, C.A., Tovar-Ramírez, D., Nolasco-Soria, H., Galaviz-Espinosa, M.A., et al. 2015. Development of digestive tract and enzyme activities during the early ontogeny of the tropical gar Atractosteus tropicus. Fish Physiology and Biochemistry, 41(5): 1075-1091.

Gao, Y., Storebakken, T., Shearer, K.D., Penn, M. \& Øverland, M. 2011. Supplementation of fishmeal and plant protein-based diets for rainbow trout with a mixture of sodium formate and butyrate. Aquaculture, 311(1-4): 233-240.

Garcia, R., La Clair, J. \& Müller, R. 2018. Future directions of marine myxobacterial natural product discovery inferred from metagenomics. Marine Drugs, 16(9): 303.

Gerber, E., Bernard, R., Castang, S., Chabot, N., Coze, F., Dreux-Zigha, A. \& Lazarelli, C. 2015. Deinococcus as new chassis for industrial biotechnology: biology, physiology, and tools. Journal of Applied Microbiology, 119(1): 1-10.

Ghanbari, M., Kneifel, W. \& Domig, K. J. 2015. A new view of the fish gut microbiome: advances from nextgeneration sequencing. Aquaculture, 448: 464-475. doi: 10.1016/j.aquaculture.2015.06.033

Gianoulis, T.A., Raes, J., Patel, P.V., Bjornson, R., Korbel, J.O., Letunic, I. \& Snyder, M. 2009. Quantifying environmental adaptation of metabolic pathways in metagenomics. Proceedings of the National Academy of Sciences, 106: 1374-1379.

Givens, C.E. 2012. A fish tale: comparison of the gut microbiome of 15 fish species and the influence of diet and temperature on its composition. Doctoral Thesis, University of Georgia, Athens.

Gonzalez, C.J., Santos, J.A., Garcia-Lopez, M.-L. \& Otero, A. 2000. Psychrobacters and related bacteria in freshwater fish. Journal of Food Protection, 63(3): 315-321.

Griffiths, E. \& Gupta, R.S. 2007. Identification of signature proteins that are distinctive of the Deinococcus-Thermus phylum. International Microbiology, 10(3): 201.

Hamer, H.M., Jonkers, D.M., Bast, A., Vanhoutvin, S.A., Fischer, M.A., Kodde, A. \& Brummer, R.-J. M. 2009. Butyrate modulates oxidative stress in the colonic mucosa of healthy humans. Clinical Nutrition, 28(1): 88-93.

He, S., Wu, Z., Liu, Y., Wu, N., Tao, Y., Xu, L. \& Ring ø, E. 2013. Effects of dietary $60 \mathrm{~g} \mathrm{~kg}^{-1}$ dried distiller's grains in least-cost practical diets on production and gut allochthonous bacterial composition of cagecultured fish: comparison among fish species with different natural food habits. Aquaculture Nutrition, 19(5): 765-772.

Holmes, B., Snell, J.J.S. \& Lapage, S.P. 1977. Revised description, from clinical isolates, of Flavobacterium odoratum Stutzer \& Kwaschnina 1929, and designation of the neotype strain. International Journal of Systematic and Evolutionary Microbiology, 27(4): 330-336.

Iizuka, T., Jojima, Y., Fudou, R., Hiraishi, A., Ahn, J.-W. \& Yamanaka, S. 2003. Plesiocystis pacifica gen. nov., 
sp. nov., a marine myxobacterium that contains dihydrogenated menaquinone, isolated from the Pacific coasts of Japan. International Journal of Systematic and Evolutionary Microbiology, 53(1): 189-195.

Ingerslev, H.-C., Strube, M.L., Von Gersdorff Jørgensen, L., Dalsgaard, I., Boye, M. \& Madsen, L. 2014a. Diet type dictates the gut microbiota and the immune response against Yersinia ruckeri in rainbow trout (Oncorhynchus mykiss). Fish \& Shellfish Immunology, 40(2): 624-633.

Ingerslev, H.-C., Von Gersdorff-Jørgensen, L., Strube, M.L., Larsen, N., Dalsgaard, I., Boye, M. \& Madsen, L. 2014b. The development of the gut microbiota in rainbow trout (Oncorhynchus mykiss) is affected by first feeding and diet type. Aquaculture, 424: 24-34.

Iveson, J.B. 1971. Strontium chloride B and EE enrichment broth media for the isolation of Edwardsiella, Salmonella and Arizona species from tiger snakes. Epidemiology \& Infection, 69(3): 323330.

Jammal, A., Bariche, M., \& Kambris, Z. 2017. Characterization of the cultivable gut microflora in wild-caught Mediterranean fish species. Current Nutrition \& Food Science, 13(2): 147-154.

Kim, S.-J., Ahn, J.-H., Lee, T.-H., Weon, H.-Y., Hong, S.B., Seok, S.-J. \& Kwon, S.-W. 2013. Reyranellasoli sp. nov., isolated from forest soil, and emended description of the genus Reyranella Pagnier et al. 2011. International Journal of Systematic and Evolutionary Microbiology, 63(9): 3164-3167.

Klindworth, A., Pruesse, E., Schweer, T., Peplies, J., Quast, C., Horn, M. \& Glöckner, F.O. 2013. Evaluation of general 16S ribosomal RNA gene PCR primers for classical and next-generation sequencingbased diversity studies. Nucleic Acids Research, 41(1): e1.

Kormas, K.A., Meziti, A., Mente, E. \& Frentzos, A. 2014. Dietary differences are reflected on the gut prokaryotic community structure of wild and commercially reared sea bream (Sparus aurata). Microbiology Open, 3(5): 718-728.

Krossøy, C., Waagbø, R. \& Ørnsrud, R. 2011. Vitamin K in fish nutrition. Aquaculture Nutrition, 17(6): 585594. doi: 10.1111/j.1365-2095.2011.00904.x

Larsen, A.M., Mohammed, H.H. \& Arias, C.R. 2014. Characterization of the gut microbiota of three commercially valuable warm-water fish species. Journal of Applied Microbiology, 116(6): 1396-1404.

Ley, R.E., Hamady, M., Lozupone, C., Turnbaugh, P.J., Ramey, R.R., Bircher, J.S. \& Knight, R. 2008.
Evolution of mammals and their gut microbes. Science, 320(5883): 1647-1651.

Li, H., Zhong, Q., Wirth, S., Wang, W., Hao, Y., Wu, S., et al. 2015b. Diversity of autochthonous bacterial communities in the intestinal mucosa of grass carp (Ctenopharyngodon idellus) (Valenciennes) determined by culture-dependent and culture-independent techniques. Aquaculture Research, 46(10): 2344-2359. doi: 10.1111/are.12391

Li, J., Ni, J., Li, J., Wang, C., Li, X., Wu, S., et al. 2014a. Comparative study on gastrointestinal microbiota of eight fish species with different feeding habits. Journal of Applied Microbiology, 117(6): 1750-1760.

Li, T., Long, M., Gatesoupe, F.-J., Zhang, Q., Li, A. \& Gong, X. 2015a. Comparative analysis of the intestinal bacterial communities in different species of carp by pyrosequencing. Microbial Ecology, 69(1): 25-36. doi: 10.1007/s00248-014-0480-8

Li, T., Li, H., Gatesoupe, F.-J., She, R., Lin, Q., Yan, X., et al. 2017. Bacterial signatures of "Red-Operculum" disease in the gut of crucian carp (Carassius auratus). Microbial Ecology, 74(3): 510-521. doi: 10.1007/ s00248-017-0967-1

Li, X., Zhu, Y., Yan, Q., Ring ø, E. \& Yang, D. 2014b. Do the intestinal microbiotas differ between paddlefish (Polyodon spathala) and bighead carp (Aristichthys nobilis) reared in the same pond? Journal of Applied Microbiology, 117(5): 1245-1252.

Li, X., Yan, Q., Xie, S., Hu, W., Yu, Y. \& Hu, Z. 2013. Gut microbiota contributes to the growth of fastgrowing transgenic common carp (Cyprinus carpio L.). Plos One, 8(5): e64577.

Liu, H., Guo, X., Gooneratne, R., Lai, R., Zeng, C., Zhan, F. \& Wang, W. 2016. The gut microbiome and degradation enzyme activity of wild freshwater fishes influenced by their trophic levels. Scientific Reports, 6: 24340.

Liu, Z., Ke, X., Lu, M., Gao, F., Cao, J., Zhu, H. \& Wang, M. 2015. Identification and pathological observation of a pathogenic Plesiomonas shigelloides strain isolated from cultured tilapia (Oreochromis niloticus). Acta Microbiologica Sinica, 55(1): 96-106.

Lozupone, C., Lladser, M.E., Knights, D., Stombaugh, J. \& Knight, R. 2011. UniFrac: an effective distance metric for microbial community comparison. The ISME Journal, 5(2): 169. doi: 10.1038/ismej.2010.133

Lubbs, D.C., Vester, B.M., Fastinger, N.D. \& Swanson, K.S. 2009. Dietary protein concentration affects intestinal microbiota of adult cats: a study using DGGE and qPCR to evaluate differences in microbial populations in the feline gastrointestinal tract. Journal of Animal Physiology and Animal Nutrition, 93(1): 113-121. 
MacFarlane, R.D., McLaughlin, J.J. \& Bullock, G.L. 1986. Quantitative and qualitative studies of gut flora in striped bass from estuarine and coastal marine environments. Journal of Wildlife Diseases, 22(3): 344-348.

Maraki, S., Sarchianaki, E. \& Barbagadakis, S. 2012. Myroides odoratimimus soft tissue infection in an immunocompetent child following a pig bite: case report and literature review. Brazilian Journal of Infectious Diseases, 16(4): 390-392. doi: 10.1016/ j.bjid.2012.06.004

Márquez-Couturier, G. \& Vázquez-Navarrete, C.J. 2015. Estado de arte de la biología y cultivo de pejelagarto (Atractosteus tropicus). Agroproductividad, 8(3): 4451.

Márquez-Couturier, G., Álvarez-González, C.A., ContrerasSánchez, W.M., Hernández-Vidal, U., HernándezFranyutti, A.A., Mendoza-Alfaro, R. \& GoytortuaBores, E. 2006. Avances en la alimentación y nutrición de pejelagarto Atractosteus tropicus. Memorias del VIII Simposium Internacional de Nutrición Acuícola, UANL, Monterrey, Nuevo León, México, pp. 446523.

Márquez-Couturier, G., Vázquez-Navarrete, C.J., Contreras-Sánchez, W.M. \& Álvarez-Glez, C.A. 2015. Acuicultura tropical sustentable: una estrategia para la producción y conservación del pejelagarto (Atractosteus tropicus) en Tabasco, México. Universidad Juárez Autónoma de Tabasco, Tabasco.

Martens, J.H., Barg, H., Warren, M. \& Jahn, D. 2002. Microbial production of vitamin B 12. Applied Microbiology and Biotechnology, 58(3): 275-285.

Martin, M. 2011. Cutadapt removes adapter sequences from high-throughput sequencing reads. EMBnet Journal, 17(1): 10-12. doi: 10.14806/ej.17.1.200

Martínez-Cruz, P., Ibáñez, A.L., Monroy-Hermosillo, O.A. \& Ramírez-Saad, H.C. 2012. Use of probiotics in aquaculture. ISRN Microbiology, 2012. doi: 10.5402/2012/916845

Martínez-Díaz, S.F. \& Pérez-España, H. 1999. Feasible mechanisms for algal digestion in the king angelfish. Journal of Fish Biology, 55(4): 692-703.

McBain, J.A., Eastman, A., Nobel, C.S. \& Mueller, G.C. 1997. Apoptotic death in adenocarcinoma cell lines induced by butyrate and other histone deacetylase inhibitors. Biochemical Pharmacology, 53(9): 13571368.

Méndez-Marin, O., Hernández Franyutti, A.A., ÁlvarezGonzález, C.A., Contreras-Sánchez, W.M. \& UribeAranzábal, M.C. 2012. Histología del ciclo reproductor de hembras del pejelagarto Atractosteus tropicus (Lepisosteiformes: Lepisosteidae) en Tabasco, México. Revista de Biología Tropical, 60(4): 1857-1871.
Miller, R.R., Minckley, W.L. \& Norris, S.M. 2005. Freshwater fishes of Mexico. University of Chicago, Chicago.

Miyake, S., Ngugi, D.K. \& Stingl, U. 2015. Diet strongly influences the gut microbiota of surgeonfishes. Molecular Ecology, 24(3): 656-672.

Moran, D., Turner, S. \& Clements, K. 2005. Ontogenetic development of the gastrointestinal microbiota in the marine herbivorous fish Kyphosus sydneyanus. Microbial Ecology, 49(4): 590-597.

Nam, Y.-D., Jung, M.-J., Roh, S.W., Kim, M.-S. \& Bae, J.-W. 2011. Comparative analysis of Korean human gut microbiota by barcoded pyrosequencing. Plos One, 6(7): e22109. doi: 10.1371/ journal.pone0022109

Nayak, S.K. 2010. Role of gastrointestinal microbiota in fish. Aquaculture Research, 41(11): 1553-1573.

Nelson, J.S., Grande, T.C. \& Wilson, M.V. 2016. Fishes of the world. John Wiley \& Sons, New Jersey.

Ni, J., Yu, Y., Zhang, T. \& Gao, L. 2012. Comparison of intestinal bacterial communities in grass carp, Ctenopharyngodon idellus, from two different habitats. Chinese Journal of Oceanology and Limnology, 30(5): 757-765. doi: 10.1007/s00343-012$1287-4$

Nielsen, H.B., Almeida, M., Juncker, A.S., Rasmussen, S., Li, J., Sunagawa, S. \& Le Chatelier, E. 2014. Identification and assembly of genomes and genetic elements in complex metagenomic samples without using reference genomes. Nature Biotechnology, 32(8): 822-828.

Nuez-Ortin, W.G., Prado, S. \& Toranzo, A.E. 2012. Antimicrobial properties of butyric acid and other organic acids against pathogenic bacteria affecting the main aquatic species. Meeting Abstract, Aqua Conference 2012, Prague.

Núñez de la Rosa, M.G. 2011. Evaluación preliminar de las poblaciones bacterianas asociadas al tracto intestinal de la tilapia (Oreochromis niloticus) expuesta a aceites esenciales de orégano en la dieta. Tesis Magister en Ciencias-Microbiología, Universidad Nacional de Colombia, Bogotá.

Onarheim, A.M., Wiik, R., Burghardt, J. \& Stackebrandt, E. 1994. Characterization and identification of two Vibrio species indigenous to the intestine of fish in cold seawater; description of Vibrio iliopiscarius sp. nov. Systematic and Applied Microbiology, 17(3): 370-379.

Owen, M.A.G., Waines, P., Bradley, G. \& Davies, S. 2006. The effect of dietary supplementation of sodium butyrate on the growth and microflora of Clarias gariepinus (Burchell 1822). Proceedings of the XII 
International Symposium Fish Nutrition and Feeding, Biarritz, France.

Pagnier, I., Raoult, D. \& La Scola, B. 2011. Isolation and characterization of Reyranella massiliensis gen. nov., sp. nov. from freshwater samples by using an amoeba co-culture procedure. International Journal of Systematic and Evolutionary Microbiology, 61(9): 21512154.

Piazzon, M.C., Naya-Català, F., Simó-Mirabet, P., PicardSánchez, A., Roig, F.J., Calduch-Giner, J.A., et al. 2019. Sex, age, and bacteria: how the intestinal microbiota is modulated in a protandrous hermaphrodite fish. Frontiers in Microbiology, 10: 2512. doi: 10.3389/fmicb.2019.02512

Pikuta, E.V., Hoover, R.B., Marsic, D., Whitman, W.B., Lupa, B., Tang, J. \& Krader, P. 2009. Proteocatella sphenisci gen. nov., sp. nov., a psychrotolerant, sporeforming anaerobe isolated from penguin guano. International Journal of Systematic and Evolutionary Microbiology, 59(9): 2302-2307.

Qi, X.-Z., Xue, M.-Y., Yang, S.-B., Zha, J.-W., Wang, G.-X. \& Ling, F. 2017. Ammonia exposure alters the expression of immune-related and antioxidant enzymesrelated genes and the gut microbial community of crucian carp (Carassius auratus). Fish \& Shellfish Immunology, 70: 485-492. doi: 10.1016/j.fsi.2017. 09.043

Ray, A.K., Ghosh, K. \& Ringø, E. 2012. Enzymeproducing bacteria isolated from fish gut: a review. Aquaculture Nutrition, 18(5): 465-492.

R Core Team. 2019. R: a language and environment for statistical computing. R Foundation for Statistical Computing, Vienna.

Reséndez-Medina, A. \& Salvadores, M.L. 1983. Contribución al conocimiento de la biología del pejelagarto Lepisosteus tropicus (Gill) y la tenguayaca Petenia splendida Günther, del estado de Tabasco. Biótica, 8: 413-426.

Rimmer, D.W. \& Wiebe, W.J. 1987. Fermentative microbial digestion in herbivorous fishes. Journal of Fish Biology, 31(2): 229-236.

Ring $\varnothing$, E., Sperstad, S., Myklebust, R., Refstie, S. \& Krogdahl, A. 2006. Characterization of the microbiota associated with intestine of Atlantic cod (Gadus morhua L.): the effect of fish meal, standard soybean meal, and a bioprocessed soybean meal. Aquaculture, 261(3): 829-841.

Ring $\varnothing$, E., Strøm, E. \& Tabachek, J.A. 1995. Intestinal microflora of salmonids: a review. Aquaculture Research, 26(10): 773-789.

Roeselers, G., Mittge, E.K., Stephens, W.Z., Parichy, D.M., Cavanaugh, C.M., Guillemin, K. \& Rawls, J.F. 2011. Evidence for a core gut microbiota in the zebrafish. The ISME Journal, 5(10): 1595-1608.
Roth, J.R., Lawrence, J.G. \& Bobik, T.A. 1996. Cobalamin (coenzyme B12): synthesis and biological significance. Annual Reviews in Microbiology, 50(1): 137-181.

Rudi, K., Angell, I.L., Pope, P.B., Vik, J.O., Sandve, S.R. \& Snipen, L.-G. 2018. Stable core gut microbiota across the freshwater-to-saltwater transition for farmed Atlantic salmon. Applied and Environmental Microbiology, 84(2): e01974-01917.

Segata, N., Izard, J., Waldron, L., Gevers, D., Miropolsky, L., Garrett, W.S. \& Huttenhower, C. 2011. Metagenomic biomarker discovery and explanation. Genome Biology, 12(6): R60. doi: 10.1186/gb-201112-6-r60

Smith, A.G., Croft, M.T., Moulin, M. \& Webb, M.E. 2007. Plants need their vitamins too. Current Opinion in Plant Biology, 10(3): 266-275.

Smith, L.S. 1980. Digestion in teleost fishes. Lectures presented at the FAO/UNDP. Training course in fish feeding technology. ACDP/REP/80/11, FAO, Rome, pp. 3-17. [http://www.fao.org/docrep/ X5738E/x5738 e02.htm]. Reviewed: June 15, 2020.

Smriga, S., Sandin, S.A. \& Azam, F. 2010. Abundance, diversity, and activity of microbial assemblages associated with coral reef fish guts and feces. FEMS Microbiology Ecology, 73(1): 31-42.

Spiteller, D., Dettner, K. \& Boland, W. 2000. Gut bacteria may be involved in interactions between plants, herbivores and their predators: microbial biosynthesis of $\mathrm{N}$-acylglutamine surfactants as elicitors of plant volatiles. Biological Chemistry, 381(8): 755-762. doi: 10.1515/bc. 2000.096

Stepanović, S., Vuković, D., Hola, V., Bonaventura, G.D., Djukić, S., Ćirković, I. \& Ruzicka, F. 2007. Quantification of biofilm in microtiter plates: overview of testing conditions and practical recommendations for assessment of biofilm production by staphylococci. Apmis, 115(8): 891-899. doi: 10.1111/j.1600-0463. 2007.apm_630.x

Sullam, K.E., Essinger, S.D., Lozupone, C.A., O'Connor, M.P., Rosen, G.L., Knight, R. \& Russell, J.A. 2012. Environmental and ecological factors that shape the gut bacterial communities of fish: a meta-analysis. Molecular Ecology, 21(13): 3363-3378.

Suttle, C.A. 2007. Marine viruses-major players in the global ecosystem. Nature Reviews Microbiology, 5(10): 801-812.

Tamaki, H., Wright, C.L., Li, X., Lin, Q., Hwang, C., Wang, S., Thimmapuram, J., Kamagata, Y. \& Liu, W.T. 2011. Analysis of 16S rRNA amplicon sequencing options on the Roche/454 next-generation titanium sequencing platform. PloS one, 6(9): e25263. doi: 10.1371/journal.pone0025263 
Theodorakopoulos, N., Bachar, D., Christen, R., Alain, K. \& Chapon, V. 2013. Exploration of DeinococcusThermus molecular diversity by novel group-specific PCR primers. Microbiology Open, 2(5): 862-872.

Thomas, F., Hehemann, J.-H., Rebuffet, E., Czjzek, M. \& Michel, G. 2011. Environmental and gut bacteroidetes: the food connection. Frontiers in Microbiology, 2: 93. doi: 10.1002/mbo3.119

Titus, E. \& Ahearn, G.A. 1988. Short-chain fatty acid transport in the intestine of an herbivorous teleost. Journal of Experimental Biology, 135(1): 77-94.

Tsuchiya, C., Sakata, T. \& Sugita, H. 2008. Novel ecological niche of Cetobacterium somerae, an anaerobic bacterium in the intestinal tracts of freshwater fish. Letters in Applied Microbiology, 46(1): 43-48.

Turnbaugh, P.J., Hamady, M., Yatsunenko, T., Cantarel, B.L., Duncan, A., Ley, R.E. \& Affourtit, J.P. 2009. A core gut microbiome in obese and lean twins. Nature, 457(7228): 480-484.

Uffen, R.L. 1997. Xylan degradation: a glimpse at microbial diversity. Journal of Industrial Microbiology and Biotechnology, 19(1): 1-6.

Uz, I. \& Ogram, A.V. 2006. Cellulolytic and fermentative guilds in eutrophic soils of the Florida Everglades. FEMS Microbiology Ecology, 57(3): 396-408.

Van Kessel, M.A.H.J., Dutilh, B.E., Neveling, K., Kwint, M.P., Veltman, J.A., Flik, G. \& den Camp, H.J.M.O. 2011. Pyrosequencing of $16 \mathrm{~S}$ rRNA gene amplicons to study the microbiota in the gastrointestinal tract of carp (Cyprinus carpio L.). AMB Express, 1(1): 41.

Verner-Jeffreys, D.W., Shields, R.J., Bricknell, I.R. \& Birkbeck, T.H. 2003. Changes in the gut-associated microflora during the development of Atlantic halibut (Hippoglossus hippoglossus L.) larvae in three British hatcheries. Aquaculture, 219(1-4): 21-42.

Verschuere, L., Rombaut, G., Sorgeloos, P. \& Verstraete, W. 2000. Probiotic bacteria as biological control agents in aquaculture. Microbiology and Molecular Biology Reviews, 64(4): 655-671.

Villamil-Diaz, L.M. \& Esguerra-Rodriguez, D. 2017. Enterococcus, Myroides, and Exiguobacterium: bacterial genus with probiotic potential for Nile tilapia (Oreochromis niloticus) culture. Acta Biológica Colombiana, 22(3): 331-339. doi: 10.15446/ abc.v22n3.59974

Villasante, A., Ramírez, C., Catalán, N., Opazo, R., Dantagnan, P. \& Romero, J. 2019. Effect of dietary carbohydrate-to-protein ratio on gut microbiota in Atlantic salmon (Salmo salar). Animals, 9(3): 89.

Vogiatzoglou, A., Smith, A.D., Nurk, E., Berstad, P., Drevon, C.A., Ueland, P.M. \& Refsum, H. 2009. Dietary sources of vitamin B-12 and their association with plasma vitamin B-12 concentrations in the general population: the Hordaland Homocysteine Study. American Journal of Clinical Nutrition, 89(4): 1078-1087.

Von Engelhardt, W., Bartels, J., Kirschberger, S., zu Düttingdorf, H.D.M. \& Busche, R. 1998. Role of short-chain fatty acids in the hindgut. Veterinary Quarterly, 20(3):52-59.

Walczak, N., Puk, K. \& Guz, L. 2017. Bacterial flora associated with diseased freshwater ornamental fish. Journal of Veterinary Research, 61(4): 445-449. doi: 10.1515/jvetres-2017-0070

Wang, A.R., Ran, C., Ringø, E. \& Zhou, Z.G. 2018. Progress in fish gastrointestinal microbiota research. Reviews in Aquaculture, 10(3): 626-640. doi: 10.1111/raq.12191

Wang, Q., Garrity, G.M., Tiedje, J.M. \& Cole, J.R. 2007. Naive Bayesian classifier for rapid assignment of rRNA sequences into the new bacterial taxonomy. Applied and Environmental Microbiology, 73(16): 5261-5267. doi: 10.1128/AEM.00062-07

Ward, N.L., Steven, B., Penn, K., Methé, B.A. \& Detrich, W.H. 2009. Characterization of the intestinal microbiota of two Antarctic notothenioid fish species. Extremophiles, 13(4): 679-685.

Wiley, E.O. 1976. The phylogeny and biogeography of fossil and recent gars (Actinopterygii: Lepisosteidae). University of Kansas, Kansas.

Wong, S., Waldrop, T., Summerfelt, S., Davidson, J., Barrows, F., Kenney, P.B. \& Rawls, J.F. 2013. Aquacultured rainbow trout (Oncorhynchus mykiss) possess a large core intestinal microbiota that is resistant to variation in diet and rearing density. Applied and Environmental Microbiology, 79: 49744984.

Wu, S., Wang, G., Angert, E.R., Wang, W., Li, W. \& Zou, H. 2012. Composition, diversity, and origin of the bacterial community in grass carp intestine. Plos One, 7(2): e30440. doi: 10.1371/journal.pone.0030440

Wyatt, L.E., Nickelson, R. \& Vanderzant, C. 1979. Occurrence and control of Salmonella in freshwater catfish. Journal of Food Science, 44(4): 1067-1073.

Xia, J.H., Lin, G., Fu, G.H., Wan, Z.Y., Lee, M., Wang, L. \& Yue, G.H. 2014. The intestinal microbiome of fish under starvation. BMC genomics, 15(1): 266. doi: 10.1186/1471-2164-15-266

Xu, J., Bjursell, M.K., Himrod, J., Deng, S., Carmichael, L.K., Chiang, H.C. \& Gordon, J.I. 2003. A genomic view of the human-Bacteroides thetaiotaomicron symbiosis. Science, 299(5615): 2074-2076.

Ye, L., Amberg, J., Chapman, D., Gaikowski, M. \& Liu, W.-T. 2014. Fish gut microbiota analysis differentiates physiology and behavior of invasive Asian carp and indigenous American fish. ISME Journal, 8(3): 541551. 
Yoon, J., Maneerat, S., Kawai, F. \& Yokota, A. 2006. Myroides pelagicus $\mathrm{sp}$. nov., isolated from seawater in Thailand. International Journal of Systematic and Evolutionary Microbiology, 56(8): 1917-1920. doi: 10.1099/ijs.0.64336-0

Received: 14 August 2019; Accepted: 7 April 2020
Zhang, X.-Y., Zhang, Y.-J., Chen, X.-L., Qin, Q.-L., Zhao, D.-L., Li, T.-G. \& Zhang, Y.-Z. 2008. Myroides profundi sp. nov., isolated from deep-sea sediment of the southern Okinawa Trough. FEMS Microbiology Letters, 287(1): 108-112. doi: 10.1111/j.1574-6968. 2008.01299.x 